\title{
Microstructure and mineralogy of lightweight aggregates produced from washing aggregate sludge, fly ash and used motor oil
}

\author{
B. González-Corrochano a ${ }^{\text {, J. Alonso-Azcárate }}{ }^{\mathrm{a}, *}$, M. Rodas ${ }^{\mathrm{b}}$, F.J. Luque ${ }^{\mathrm{b}}$, J.F. Barrenechea ${ }^{\mathrm{b}}$ \\ ${ }^{a}$ Facultad de Ciencias del Medio Ambiente, Universidad de Castilla-La Mancha, Avenida Carlos III, s/n, 45071 Toledo, Spain \\ ${ }^{\mathrm{b}}$ Departmento de Cristalografia y Mineralogía. Universidad Complutense de Madrid, Ciudad Universitaria, 28040 Madrid, Spain
}

Keywords:

Lightweight aggregate

Microstructure

Mineralogy

Sintering

\begin{abstract}
A B S T R A C T
The microstructures and mineralogical compositions of lightweight aggregates (LWAs) manufactured with washing aggregate sludge (WS), fly ash (FA) and used motor oil (UMO) have been studied. Most LWAs with WS and FA exhibited an external layer and a glassy core with isolated pores. LWAs with WS and UMO did not present external shells or signs of bloating. Iron oxides, within the external layer, and pyrrhotite, in the inner glass, were observed. The mineralogical analyses revealed the neo-formation of plagioclase and pyroxene, along with minor gehlenite. Some relationships could be established: (i) the presence of larger pores is related to a decrease in the dry particle density values, (ii) when the LWA lacks the external layer, the water absorption values were dependent on the size and amount of each type of pore (open or closed), and (iii) the neo-formation of Ca-plagioclase and the consumption of quartz improved the compressive strength values.
\end{abstract}

\section{Introduction}

Lightweight aggregates (LWAs) are granular and porous materials with a particle density typically not greater than $2.00 \mathrm{~g} / \mathrm{cm}^{3}$ or with a loose bulk density $\left(\rho_{\mathrm{b}}\right)$ not greater than $1.20 \mathrm{~g} / \mathrm{cm}^{3}$ [1]. Artificial LWAs can be formed by rapid heating at high temperatures of materials that have the ability to expand. Their origin can be: (i) natural sources such as volcanic rocks $[2,3]$ and/or sedimentary rocks [4] and (ii) thermal treatment of waste materials and/or industrial by-products, such as mining wastes [5,6] and fly ash [7-9].

Due to their typically low density, good thermal and acoustic insulation, and good fire resistance properties, LWAs have become a focus of interest. In fact, they are an essential component in a variety of building materials such as prefabricated structural units, lightweight concretes, especially in high-rise buildings, as well as track ballasts and road coatings, along with bituminous materials and other geotechnical applications [10].

Concrete can be defined as the product resulting from the binding of aggregate particles or fragments (lightweight or dense) with a binder, usually artificial cement, and water. The term lightweight concrete (LWC) is used for concrete with a density of less than about $1800 \mathrm{~kg} / \mathrm{m}^{3}$ [11].

Swamy and Lambert [12] showed the importance of the microstructure and porosity for the main physical properties (density, compressive strength and water absorption) of artificial light-

\footnotetext{
* Corresponding auth or. Tel: +34 625168760; fax: +34925268840

E-mail address: jacinto.alonso@uclm.es (J. Alonso-Azcárate).
}

weight aggregates. In turn, the mix design and the properties of fresh and hardened concrete, such as workability, shrinkage and creep, are also closely related to the size and distribution of pores in the aggregate.

Feret's hypothesis [13], whereby the mineralogical nature of the aggregates had no influence on the behavior of hardened concrete, was accepted by most authors until the 1950s [14]. Farran [15] showed that the mineralogical composition is the main factor to consider in the study of concrete fracture under the action of external forces, because the mineralogy of the aggregate fundamentally determines the adhesive behavior between the cement paste and the aggregate. It is also probably a determining factor in the mechanical resistance of concrete subjected to internal stresses produced by physical agents such as ice [14].

Because concrete is the main building material used in high-rise apartment and public buildings [16], it is evident that knowledge about the microstructure and mineral phases of the aggregates which are used to manufacture it is of crucial importance.

Until the 1980s, very little was known about the pore structure of lightweight aggregates: Haydite aggregates were studied by Richart and Jensen [17] by optical microscopy, but limited to a magnification of $250 \times$. Swamy and Lambert [12] presented a detailed study of the microstructure of Lytag pellets, an artificial lightweight aggregate manufactured from sintered pulverized fuel ash. Zhang and Gjørv [18] investigated various types of expanded clays and sintered fly ash lightweight aggregates and found that the density varied with differences in both the macroscopic and microscopic pore structures. 
This paper is a continuation of a previous work [8] in which artificial lightweight aggregates were manufactured using washing aggregate sludge (WS) from a gravel pit, fly ash (FA) and used motor oil (UMO) from cars. Two conditions are necessary to achieve an appropriate expanded material [3]: it must contain substances that release gases at high temperature (T1) and a plastic phase with the appropriate viscosity must be produced so it can trap released gases at temperature T1. The used motor oil (UMO) and fly ash (FA) were added to the washing aggregate sludge (WS) with the primary objective to release gases at the heating temperatures, the first condition to achieve appropriate LWAs. The second condition is provided by the WS.

The products obtained were classified as lightweight aggregates in accordance with the UNE-EN-13055-1 [1] standard. Considering the results obtained for compressive strength $(S)$, and also the values of loose bulk density $\left(\rho_{\mathrm{b}}\right)$ and water absorption $\left(\mathrm{WA}_{24 \mathrm{~h}}\right)$, the manufactured products could have the same or similar applications as Arlita G3 and/or F3, two Spanish commercial lightweight aggregates. These applications could include insulation, geotechnical uses, horticulture, gardening and/or prefabricated lightweight structures and lightweight insulating concretes.

The aim of this work is to carry out a detailed study of the microstructure and mineral phases of selected LWAs, to establish relationships between the values of the main physical properties (density, compressive strength and water absorption) of the LWAs and their microstructure and mineralogy.

\section{Materials and methods}

A total of fifteen types of LWAs were manufactured in a previous study [8] from which 11 different types were selected (Table 1). Aggregates of type 3.F(3) were manufactured with a $75: 25$ proportion (wt.\%) of washing aggregate sludge:fly ash (WS:FA), whereas types $3 . F(2)$ were prepared using a 50:50 ratio. Types 3.Ac were manufactured with a 97.5:2.5 ratio of washing aggregate sludge:used motor oil from cars (WS:UMO). These mixtures were milled to a grain size of less than $200 \mu \mathrm{m}$ [19]. A controlled amount of water was added to the ground mixtures and they were extruded. Cylinders of $1.5 \mathrm{~cm}$ of length were cut and rolled by hand. LWAs were manufactured in a rotary kiln in groups of 25 pellets. The heating temperatures $\left(T_{\text {heating }}\right)$ were $1150^{\circ} \mathrm{C}, 1175^{\circ} \mathrm{C}$, $1200^{\circ} \mathrm{C}$ and $1225^{\circ} \mathrm{C}$ for dwell times of 10 and 15 min [8].

The characterization of the raw materials and the physical properties of the LWAs were reported in detail in González-Corrochano et al. [8]. The main constituents of the washing aggregate sludge were silica and alumina oxides (Table 2). Calcium oxide was also important, due to the presence of carbonate minerals in the sample. The $\mathrm{SiO}_{2}$ content corresponded mostly to quartz and phyllosilicates present in the WS; $\mathrm{Al}_{2} \mathrm{O}_{3}$ and $\mathrm{FeO}+\mathrm{Fe}_{2} \mathrm{O}_{3}$ contents also corresponded to phyllosilicates. $\mathrm{Na}_{2} \mathrm{O}$ and $\mathrm{K}_{2} \mathrm{O}$ contents were mainly attributed to the feldspars and to the interlayer cations of clay minerals [10]. In the fly ash, $\mathrm{SiO}_{2}$ and $\mathrm{Al}_{2} \mathrm{O}_{3}$ were the main oxides; $\mathrm{FeO}+\mathrm{Fe}_{2} \mathrm{O}_{3}$ were also important (Table 2). $\mathrm{SiO}_{2}$ and $\mathrm{Al}_{2} \mathrm{O}_{3}$ contents were mostly due to mullite and quartz, and $\mathrm{FeO}+\mathrm{Fe}_{2} \mathrm{O}_{3}$ came from hematite and magnetite.

Bloating index (BI) expresses the volume change after firing of LWAs and it was calculated following the equation: $B I=100 \times$ $\left(d_{2}-d_{1}\right) / d_{1}$, where $d_{1}$ and $d_{2}$ are the diameters of granules before and after firing, respectively, [10]. Dry particle density $\left(\rho_{\text {rd }}\right)$ is the relationship between the mass of a sample of aggregates dried in an oven and the volume these aggregates occupy in water, including the watertight internal pores and the pores available to water [20]. $\rho_{\text {rd }}$ and $24 \mathrm{~h}$ water absorption $\left(\mathrm{WA}_{2 \mathrm{th}}\right)$ were determined using the procedure described by Norm UNE-EN-1097-3 [20]. Compressive strength is given by Li et al. [21] as: $S=(2.8 P C) /\left(\pi X^{2}\right)$, where
$P C$ is the fracture load occurring rupture and $X$ is the distance between loading points. Tests of $\mathbf{B I}, \rho_{\text {rd }}, W^{24 h}$ and $S$ were carried out on samples of 25 pellets. Some LWAs manufactured with 75\%:25\% and 50\%:50\% proportions of WS:FA, heated at different temperatures and dwell times, were expanded LWAs $(\mathbf{B I}>0)$.

The first selected sample was type $3 . F(3)$, heated at $1175^{\circ} \mathrm{C}$ for a dwell time of $10 \mathrm{~min}(3 . F(3)-1175-10)$, because it had the highest bloating index $(\mathbf{B I}=11.17 \%$, Table 1$)$. Since external morphological differences exist between particles sintered in the rotary kiln in the same group of 25 pellets (i.e. under the same sintering conditions), three distinct varieties were chosen: (i) LWAs without apparent expansion or shell and a non-vitrified surface (variety $A, 40 \%$ in the sample of 25 pellets, approximately; Fig. 1a); (ii) LWAs with a clear shell that is half-broken (variety $B, 45 \%$ in the sample; Fig. 1b); and (iii) clearly expanded LWAs with a vitrified surface (variety $C, 15 \%$ in the sample, approximately; Fig. 1c). Type 3.F(2), heated at $1225^{\circ} \mathrm{C}$ for $15 \mathrm{~min}(3 . F(2)-1225-15)$, was the second LWA selected, since its BI is also positive (Table 1) and its composition is different from the previous one. In order to compare the effect of temperature on the microstructure and mineralogy of these LWAs, 3.F(3)-1150-10, sintered at a lower temperature than the first selected sample, and 3.F(2)-1150-15, 3.F(2)-1175-5 and 3.F(2)-1200-5, sintered at lower temperatures than the second selected LWA, were chosen. Additionally, $3 . F(3)$ heated at $1150^{\circ} \mathrm{C}$ for $15 \mathrm{~min}(3 . F(3)-1150-5)$ and $3 . F(2)$ heated at $1150^{\circ} \mathrm{C}$ and $1225^{\circ} \mathrm{C}$ for $10 \mathrm{~min}$ (3.F(2)-1150-0 and $3 . F(2)-1225-0$, respectively), were studied in order to determine the influence of the dwell time (Table 1). LWAs manufactured with used motor oil (Type 3.AC), sintered at $1150^{\circ} \mathrm{C}$ for $10 \mathrm{~min}(3 . A c-1150-10)$ and at $1175^{\circ} \mathrm{C}$ for $15 \min (3 . A c-1175-15)$, were chosen because they showed the lowest and highest values of compressive strength, respectively, within that composition (Table 1).

The surface texture, pore structure and total mineralogy of these different aggregates are investigated in this work.

Each particle was divided into two halves using a Nannetti ${ }^{\bullet} \mathrm{FM}$ 96 press. One specimen was then glued onto a $\mathrm{Cu} / \mathrm{Zn}$ stub with colloidal silver and gold-coated. The surface morphology of the fractured specimens was examined using a JEOL JSM-6400 scanning electron microscope (SEM) coupled with an energy-dispersive $\mathrm{X}$-ray (EDX) analyzer. The SEM accelerating voltage was $20 \mathrm{kV}$.

The EDX spectra show only a semi-quantitative chemical analysis; therefore, electron microprobe analyses (EMPA) were carried out using a JEOL JXA-8900 M WD/ED. The LWAs were cut and embedded in an epoxy resin under vacuum conditions, and the resulting slabs were polished and carbon-coated. All the analyses were conducted with an accelerating voltage of $15 \mathrm{kV}$ and a spot size of $1 \mu \mathrm{m}$. Backscattered electron microscope (BSEM) images were taken during the microprobe study, which provided textural information.

The bulk mineralogy (BM) was determined by X-ray diffraction (XRD) after grinding and homogenization of the samples (three entire pellets of each type) to $<53 \mu \mathrm{m}$, except for variety $B$ of $3 . F(3)$ 1175-10 (Fig. 1b), for which the external layer and the inner core materials were analysed separately. Random-oriented powders were examined on an X'Pert Pro diffractometer, using $\mathrm{Cu} K \alpha$ radiation, an accelerating voltage of $45 \mathrm{kV}$ and a current of $40 \mathrm{~mA}$. The slit system (soller-mask-divergence-anti-scatter slits) was formed by $0.04 \mathrm{rad}-10 \mathrm{~mm}-1 / 8^{\bullet}-1 / 4^{\bullet}$ slits. The step size was 0.01 $\left({ }^{\bullet} \theta\right.$ ) and the time per step was $40 \mathrm{~s}$ (scan speed of $0.05^{\bullet} 2 \theta / \mathrm{s}$ ).

\section{Results and discussion}

\subsection{Particle shape and surface texture}

The shape and the surface texture of aggregate particles have an influence on the properties of concrete (greater for fresh than for hardened concrete [11]). 


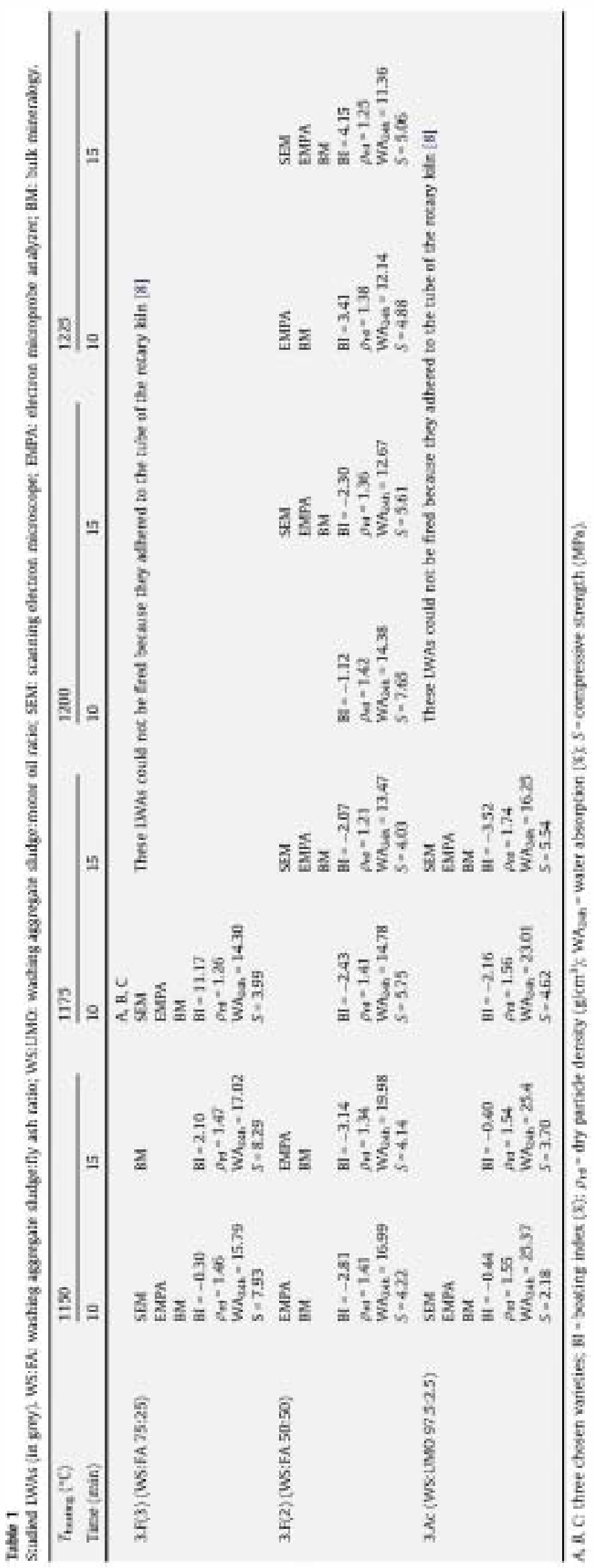

Visual observation of the LWAs clearly shows that they differ considerably in surface texture and particle shape. This is even evident for LWAs having the same composition, sintered at the same heating temperature and dwell time, such as varieties $A$ (Fig. 1a), $B$ (Fig. 1b) and $C$ (Fig. 1c) of type 3.F(3)-1175-10. The differences between these three varieties are due to the existence of a slight temperature gradient in the heating area (central zone) of the rotary kiln tube. In this area, the temperature selected by the user is reached at the center (approximately $10 \mathrm{~cm}$ of length) and decreases by up to a maximum of $50^{\circ} \mathrm{C}$ towards the lateral areas (Fig. 2, [8]). Each variety was symmetrically located with respect to the center of the tube. Variety $C$ (Fig. 1C), with well-vitrified shells, was sintered right at the center. Variety $B$ (Fig. 1b) was located to the right and left of variety $C$ (Fig. 1c). Variety $A$ (Fig. 1a), with a non-vitrified surface, was sintered in the two areas furthest from the center (i.e. from variety $C$ ): the areas closest to the entrance and to the exit of the tube (Fig. 2).

Like some commercial lightweight aggregates (e.g. Litcon [22]), all the types, except for variety $B$ of $3 . F(3)-1175-10$ (Fig. 1b) and some specimens of $3 . F(2)-1200-15$ and $3 . F(2)-1225-10 / 15$, are rounded in shape and reasonably isodiametric. Macroscopically, their surface textures are relatively smooth (Fig. 1a). These features may entail a lower concrete production cost than for elongated, angular particles, since the former generally require less cement paste to produce workable concrete mixtures [11].

The exceptions, primarily variety $B$, are also rounded, but irregular in length and diameter (Fig. 1b). Their surface textures are almost completely homogeneous macroscopically, except for a big fissure, containing vitrified material, which is present in the outer region.

A high roughness of the aggregate surface may increase the cement-aggregate physical bond strength [18] and, therefore, variety $B$ (Fig. 1b) could present higher bond strength with the cement paste than the other LWAs studied. This would only occur at an early age because, at a later age, when there is a stronger chemical bond, the texture effect becomes less important [11].

\subsection{LWAs manufactured with $75 \%$ of washing aggregate sludge and 25\% of fly ash (types 3.F(3))}

\subsubsection{SEM results}

Typical SEM micrographs of the LWAs studied are shown in Fig. 3. 3.F(3)-1150-10 does not have a distinct external layer (Fig. 3a). The aggregate material is produced with different degrees of sintering: both individual particles and growth of necks between them can be observed within the same region of the LWA (zoom in Fig. 3a). There are no clear signs of expansion. However, at a higher temperature, 3.F(3)-1175-10/variety $A$ (Fig. 1a) presents a thick, dense external layer, which is not entirely well-differentiated and is not composed of vitreous material (Fig. 3b). Its core is relatively small; it is made up of glassy material and shows signs of expansion (bloating). The dense external layer of 3.F(3)-1175-10/ variety $B$ (Fig. 1b) is well-differentiated (Fig. 3c). The shell material is sintered and clearly shows the growth of necks between the raw material particles (Fig. 3e). Unlike the external layer, the internal material is vitrified and shows signs of bloating. 3.F(3)-1175-10/ variety $C$ (Fig. 1c) shows a very thin, discontinuous external layer (Fig. 3d). The outer surface of the granules, as well as the interior thereof, is fully vitrified (Fig. 3f). Like varieties $A$ (Fig. 3b) and $B$ (Fig. 3C), it presents clear signs of expansion, with large-size pores.

As shown in Fig. 3b-d, the thickness of the external layer of LWAs with $25 \%$ of fly ash varies from aggregate to aggregate ( $\sim 50-2000 \mu \mathrm{m}$ thick) and also between different parts within the same aggregate. This thickness tends to decrease as the heating temperature increases (the shell of variety $C$, Fig. 3d, sintered in the most central area of the tube, is thinner than the shells of vari- 
Table 2

Chemical composition of the washing aggregate sludge (WS) and the fly ash (FA). LOI: loss on ignition (at $100{ }^{\circ} \mathrm{C}$ ) [8]

\begin{tabular}{|c|c|c|c|c|c|c|c|c|c|c|c|}
\hline Samples & $\mathrm{SiO}_{2}$ & $\mathrm{Al}_{2} \mathrm{O}_{3}$ & $\mathrm{FeO}$ & $\mathrm{Fe}_{2} \mathrm{O}_{3}$ & $\mathrm{CaO}$ & $\mathrm{MgO}$ & $\mathrm{K}_{2} \mathrm{O}$ & $\mathrm{Na}_{2} \mathrm{O}$ & $\mathrm{SO}_{3}$ & $\mathrm{TiO}_{2}$ & LOI \\
\hline WS & 53.59 & 10.48 & 1.34 & 1.49 & 13.03 & 1.74 & 2.51 & 0.81 & 0.02 & 0.44 & 15.72 \\
\hline FA & 34.88 & 22.53 & 7.40 & 8.22 & 2.58 & 0.62 & 1.22 & 0.11 & 0.46 & 0.50 & 21.61 \\
\hline
\end{tabular}



(a)

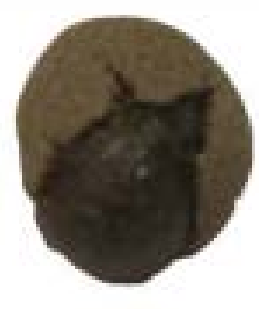

(b)

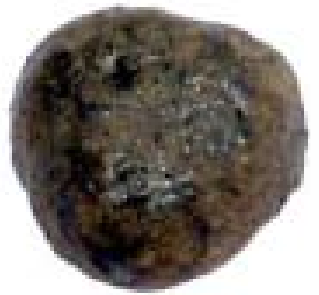

(c)
Fig. 1. (a) Variety $A$ of $3 . F(3)-1175-10$; (b) variety $B$ of 3.F(3)-1175-10; (c) variety $C$ of 3.F(3)-1175-10.

eties $A$, Fig. $3 b$, and $B$, Fig. $3 c$ ). Temperature gradients inside the molten aggregate during the heating process have been demonstrated by previous studies [22] and the above-mentioned structures could be the result of these gradients. The highest temperature is reached in the inner core, as the material appears vitrified (contrary to the external layer, which does not). This could be attributed to the fact that partial pyrolysis/combustion of the fly ash organic matter (total organic carbon $=7.8 \%,[8]$ ) releases energy in the form of heat, as may be inferred from thermogravimetry-differential thermal analysis (TG-DTA) [8]. The released heat would be stored inside the aggregate and would promote melting from the core to the outermost areas, until the surface of the granule is reached. If a large amount of gas is generated within the LWA, before the whole pellet is in the plastic state, fissures will form, as in the case of variety $B$ (Fig. 1b).

The size of the inner pores is heterogeneous and, as mentioned in previous studies [23], large pores are usually located at the core, where the expansion begins, while smaller pores are found in the external area. The maximum inner pore diameter of variety $A$ is approximately $2000 \mu \mathrm{m}$ (Fig. 3b), but in varieties $B$ and $C$ the pores can reach up to $4000 \mu \mathrm{m}$ and $7000 \mu \mathrm{m}$, respectively (Fig. 3c and d).
The $A$ variety (Fig. 3b) has a more uniform distribution of smaller pores as compared to the rest of the samples within this type (Fig. 3c and d). Despite the differences in the sizes and distribution of pores, they are generally not interconnected.

Chiou et al. [24] reported that the macro properties and the microstructure of LWAs are affected by processes such as water evaporation, oxidation of organic matter and decomposition of inorganic salts. During the process of sintering lightweight aggregates manufactured with washing aggregate sludge and fly ash, a weight loss occurred as a result of these processes, in addition to the expulsion of water adsorbed onto the clay minerals and to the gas evolution produced by the reaction of $\mathrm{Fe}_{2} \mathrm{O}_{3}$ [8]. Since the loss on ignition (LOI) of the LWAs studied is positively correlated with the heating temperature [8] and they have been manufactured at different temperatures (Table 1), they present the microstructural differences shown in Fig. 3a-d.

The generation of gas and the increase in the inner temperature lead to a decrease in the viscosity of the molten phase and to an increase in the gas pressure. The diameters of the pores in the LWAs studied and the thickness of the layers formed thereon are dependent on the above-mentioned balance between the gas pressure and the viscosity of the molten phase [25]: the largest pores are formed when the highest gas pressure is achieved within the temperature range at which the viscosity is appropriate for the gas not to escape through the LWAs by bubbling [3]. Previous studies $[3,26,27]$ reported that increasing the inner temperature and the generation of molten ingredients in the green pellets effectively accelerate the formation of a glass phase. This is clearly observed in 3.F(3)-1175-10/variety $C$ (Fig. 3d), as it has been manufactured at the highest heating temperatures among the aggregates with the same proportion of fly ash (Table 1).

The EDX spectra show that the external layers of $3 F(3)-1175-10 /$ variety $B$ (Fig. $3 c$ ) are chemically homogeneous (points 1 and 2 , Table 3; only two of six measures are reported here). The vitrified

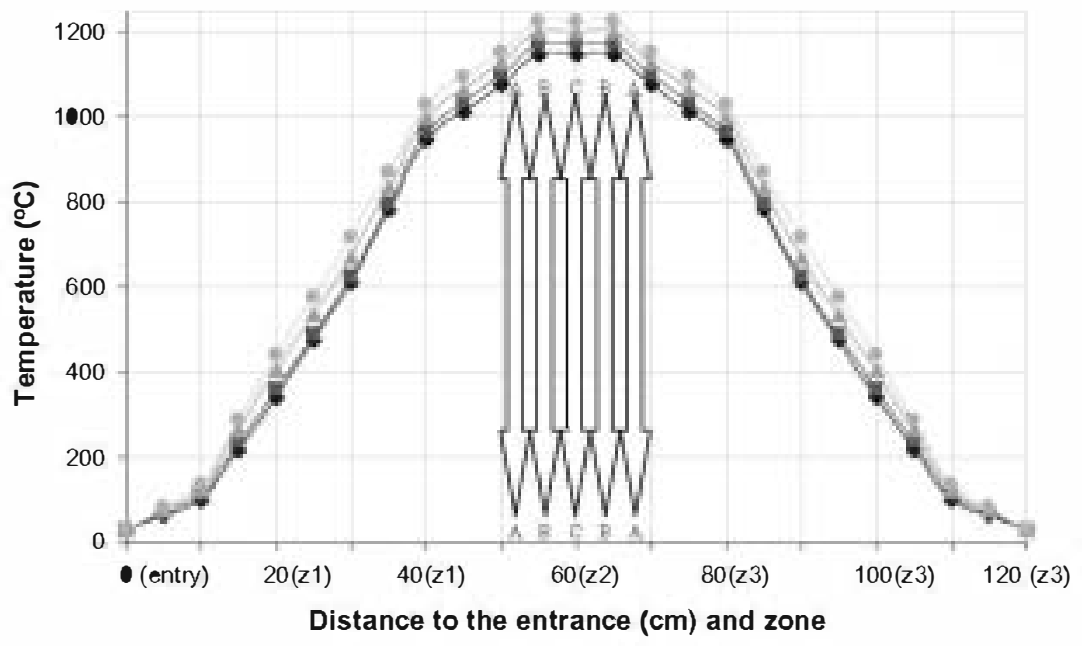

$\bullet \mathrm{Tsl}=1150^{\circ} \mathrm{C} \longrightarrow \mathrm{Tsl}=1175^{\circ} \mathrm{C} \longrightarrow \mathrm{Tsl}=120 \bullet^{\circ} \mathrm{C} \approx \mathrm{Tsl}=1225^{\circ} \mathrm{C}$

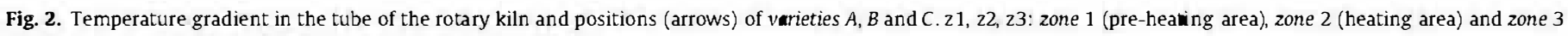
(cooling area), respectively. TsI: selected temperature by the user. 
(a)

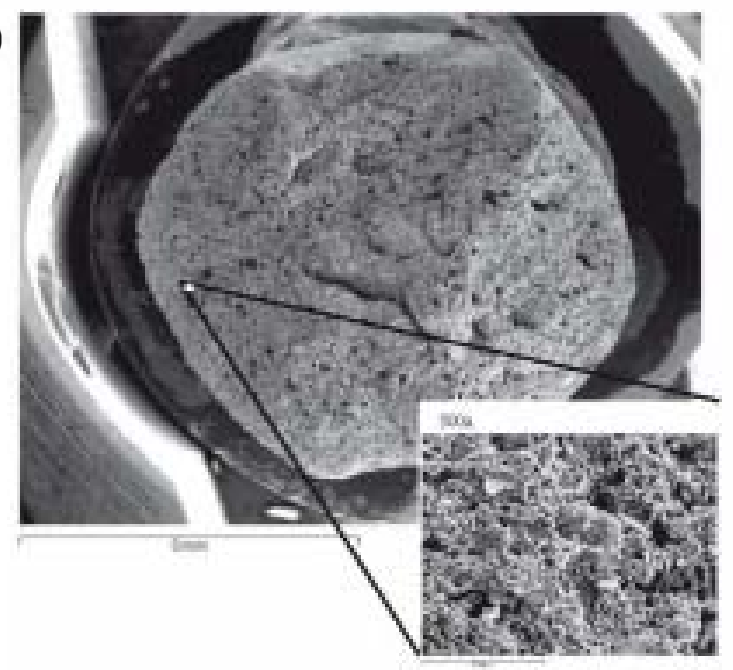

(c)

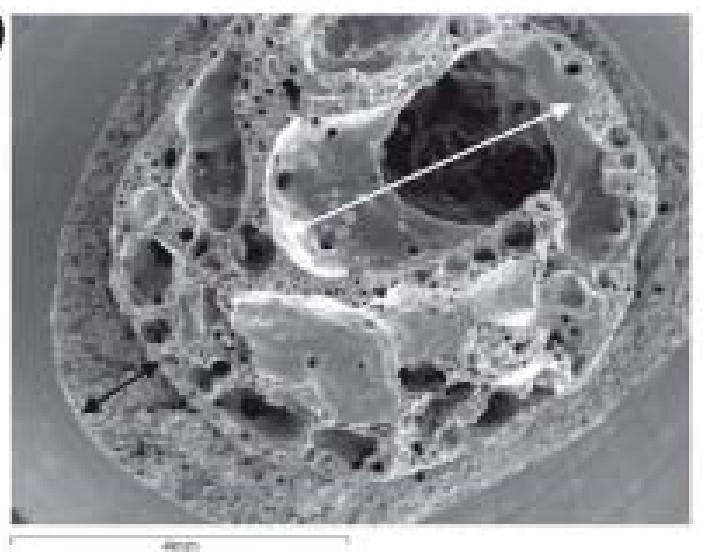

(e)



(b)

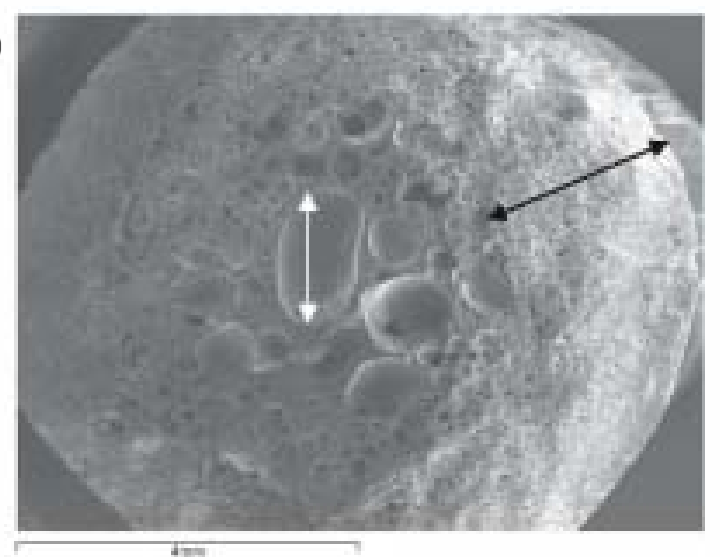

(d)

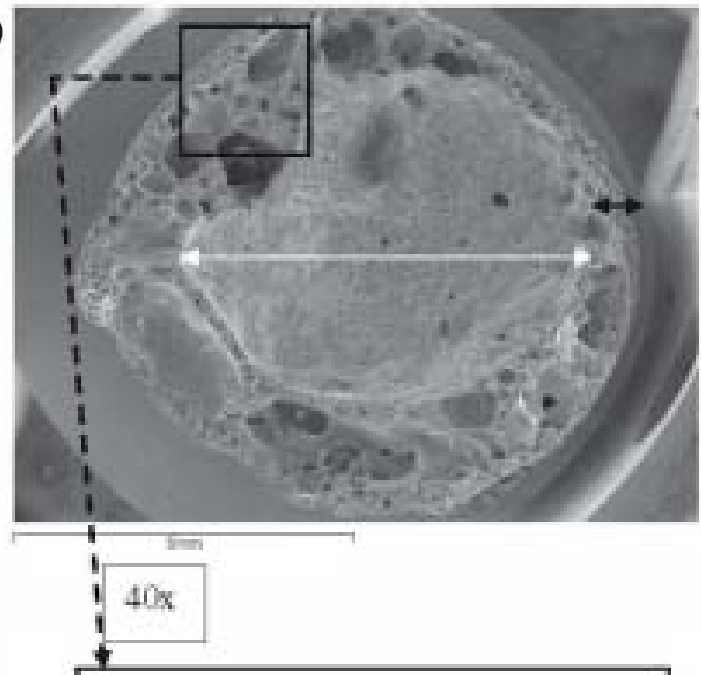

(f)

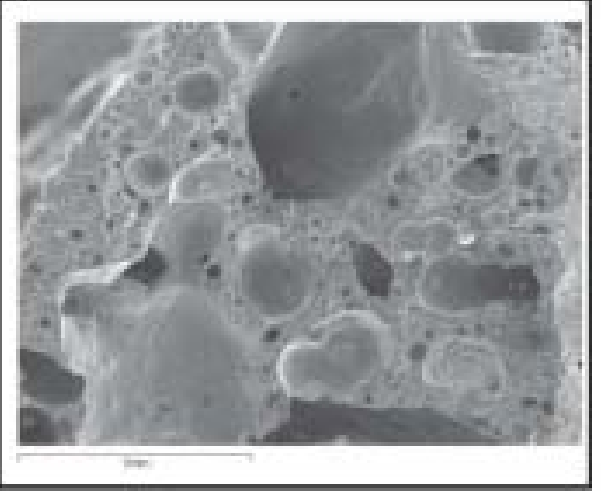

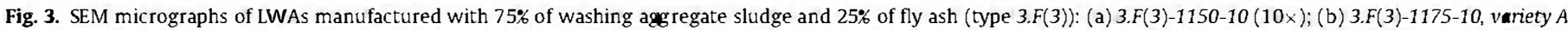

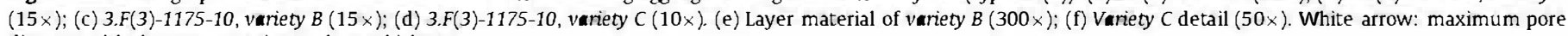
diameter; black arrow: maximum layer thickness.

material in the core is also chemically homogeneous (points 7 and 8 , Table 3 ), but it is different from the crystalline compounds found in the inner pore walls (points 3-6, Table 3, Fig. 4a-c). These crystals have high $\mathrm{S}$ and Fe contents (with low $\mathrm{Si}, \mathrm{Al}$ and Ca contents, with respect to the matrix composition (points 7 and 8, Table 3). The sulfur-bearing phases only appear inside the pores, particularly on the walls, but not in the rest of the core material, as revealed by the analysis of points 7 and 8 (Table 3). They are not found in the external shell either. These pseudo-hexagonal crystals, with jagged edges that form accordion textures (Fig. $4 \mathrm{~b}$ and d), may be neo-formed crystals of pyrrhotite ( $\mathrm{Fe}_{1_{-}} \mathrm{S}$, stable at high temperatures). The chemical composition in different areas of 3.F(3)-1150-10 (the type without an external layer) is quite homogeneous, with no S present (areas 9 and 10, Table 3).

\subsubsection{EMPA results}

The back-scattered electron (BSE) images obtained during the EMPA study show that, within 3.F(3)-1150-10 (Fig. 3a) and within the external layer of variety $B$ (Fig. $3 c$ ), Fe oxides (point 1 , Table 4 , and point 2 , Table 4 , respectively) appear as rounded aggregates 


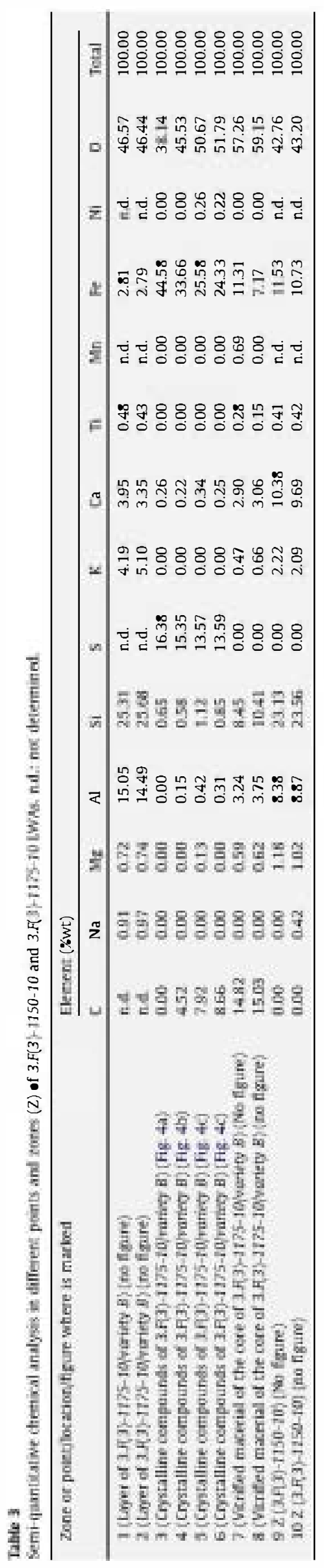

(Fig. 5a), reaching up to $40 \mu \mathrm{m}$ in diameter. It is worth noting that vitrified material with relatively high amounts of $\mathrm{Si}$ and $\mathrm{Ca}$ oxides was found, especially in the core of variety $B$ (point 3, Table 4) and in variety $C$ (point 4 , Table 4 ).

The presence of varying amounts of pyrrhotite, always located in the pore walls within the inner glassy core of the aggregates, is supported by the chemical analysis shown in Table 5, which corresponds to the points marked in Fig. Sb-c. González-Corrochano et al. [8] reported traces of pyrite $\left(\mathrm{FeS}_{2}\right)$ in the fly ash. This mineral could release gas, causing bloating as a result of any of the following reactions [28]:

$$
\begin{aligned}
& \mathrm{FeS}_{2} \leftrightarrow \mathrm{FeS}+\mathrm{S} \\
& 2 \mathrm{FeS}+3 \mathrm{O}_{2} \leftrightarrow 2 \mathrm{FeO}+2 \mathrm{SO}_{2} \uparrow \\
& \mathrm{S}+\mathrm{O}_{2} \leftrightarrow \mathrm{SO}_{2} \uparrow,
\end{aligned}
$$

Therefore, pyrrhotite could be generated from the heating of pyrite according to reaction (1). It was found that the higher the temperature and the vitrification degree of the inner material, the greater the neo-formation of FeS. This is also corroborated by the fact that pyrrhotite is absent from 3.F(3)-1150-10 (Fig. 3a), which was manufactured at the lowest heating temperature-dwell time and does not present vitrified material. As reported by Huang et al. [29], where high temperatures resulted in vitrification, new voids could show an absence or shortage of oxygen (only the $\mathrm{O}_{2}$ released from the reaction represented by $6 \mathrm{Fe}_{2} \mathrm{O}_{3} \rightarrow 4 \mathrm{Fe}_{3} \mathrm{O}_{4}+\mathrm{O}_{2}$, since the fly ash also contains hematite); moreover, after the glassy phase forms, oxygen cannot enter the mass [27]. These would be the most favorable conditions to prohibit oxidation of pyrrhotite.

In turn, the iron oxides observed in 3.F(3)-1150-10 (Fig. 3a) and in the external layer of variety $B$ (Fig. 3c) could also be generated according to reactions $(1)+(2)$, since the access of $\mathrm{O}_{2}$ is less restricted, as the material is not vitrified (Fig. $3 \mathrm{a}$ and e). The spherical structures of the iron oxides could be formed after framboidal pyrites. These structures could also be magnetite $\left(\mathrm{Fe}_{2} \mathrm{O}_{4}\right)$ framboids, since this mineral was a primary component of the fly ash [8].

\subsubsection{Mineralogy results}

Several crystalline phases were determined in the $3 . F(3)$ samples (Table 6 and Fig. 6).

All the LWAs contain quartz $\left(\mathrm{SiO}_{2}\right)$, derived from the raw materials (washing aggregate sludge and fly ash, [8]), and, due to its high melting point $\left(1610^{\circ} \mathrm{C}\right)$, it is preserved at the heating temperatures used in the manufacturing of the LWAs $\left(1150-1175^{\circ} \mathrm{C}\right)$. There is a significant decrease in the intensity of the quartz peak height as the heating temperature increases. The decrease in the amount of quartz is related to its consumption during the formation of other crystalline phases and/or additional glassy material [23].

Plagioclases (with mainly anorthitic composition, $\mathrm{CaAl}_{2} \mathrm{Si}_{2} \mathrm{O}_{8}$ ) are also found in all the samples analysed. This is in agreement with the results from previous studies [30], in which the formation of anorthite in ceramic wares manufactured with fly ash and $\mathrm{Ca}(\mathrm{OH})_{2}$ begins in the temperature range $1000-1100^{\circ} \mathrm{C}$. Although the raw materials used in this study do not contain $\mathrm{Ca}(\mathrm{OH})_{2}$, which decomposes into $\mathrm{CaO}(\mathrm{s})$ (and $\mathrm{H}_{2} \mathrm{O}(\mathrm{g})$ ) at $512{ }^{\circ} \mathrm{C}$ [31], the WS contains calcite $\left(\mathrm{CaCO}_{3}\right)$, which also decomposes into $\mathrm{CaO}(\mathrm{s})$ and $\mathrm{CO}_{2}(\mathrm{~g})$ [32], and which could be consumed during the formation of anorthite at higher temperatures. The amount of plagioclases determined by XRD increases as the temperature increases: in variety $B$, the internal (vitrified) material contains higher amounts than the external (non-vitrified) layer (Fig. $1 \mathrm{~b}, 3 \mathrm{c}$ and $3 \mathrm{e}$ ) and variety $C$ (manufactured in the tube area with the highest temperature) (Figs. 1c and 3d) shows higher contents than variety $A$ (heated towards the lateral areas) (Figs. 1a and $3 \mathrm{~b}$ ). These results agree with those of the EMPA analysis, since high amounts of $\mathrm{Si}$ and $\mathrm{Ca}$ oxides 
(a)

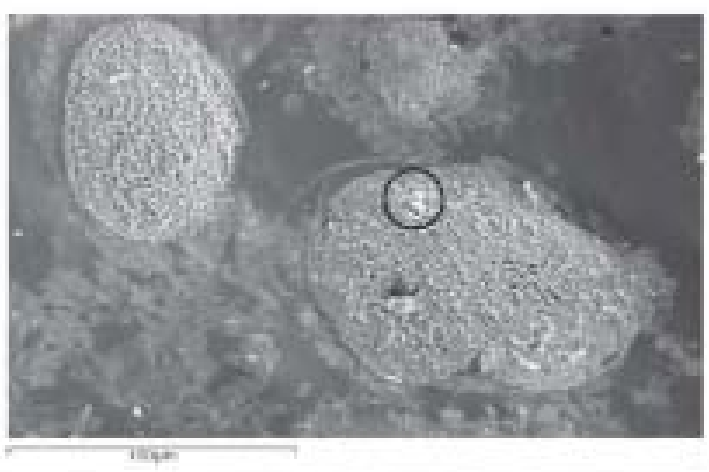

(c)

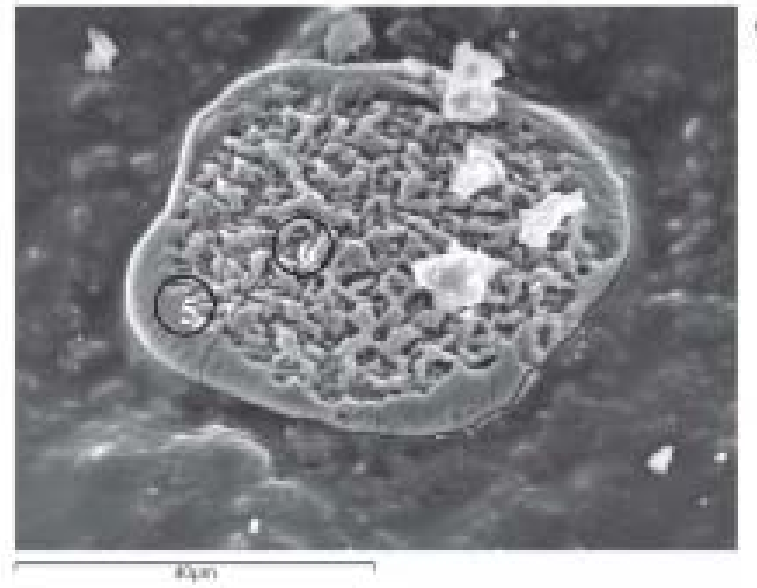

(b)

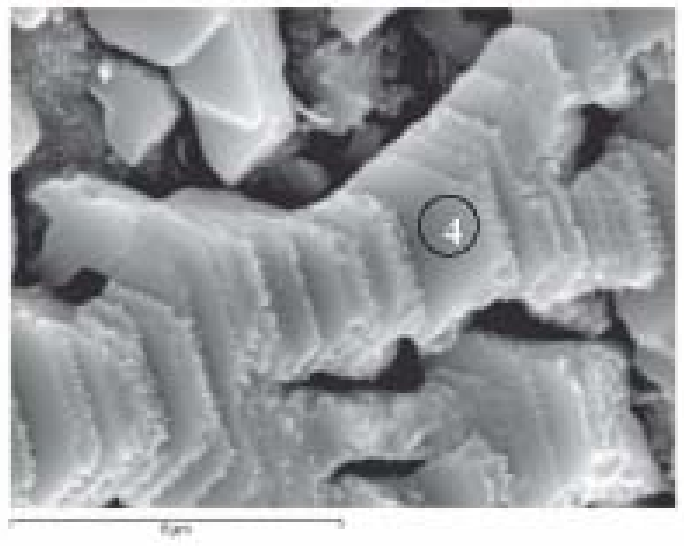

(d)

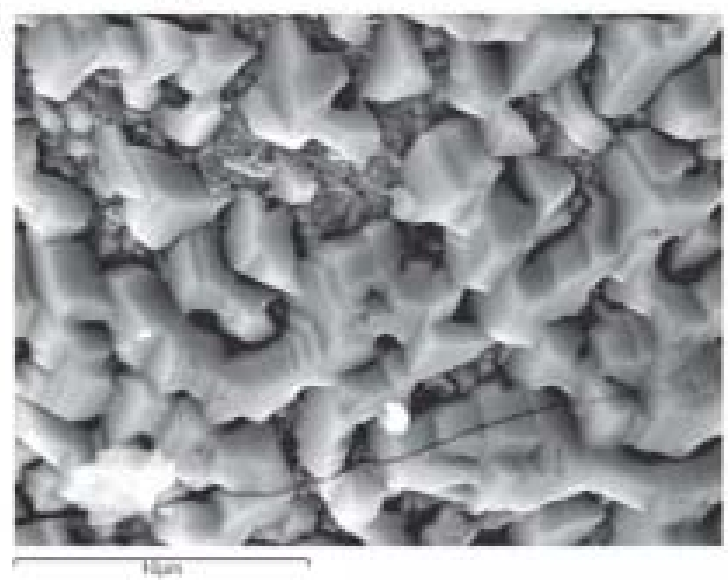

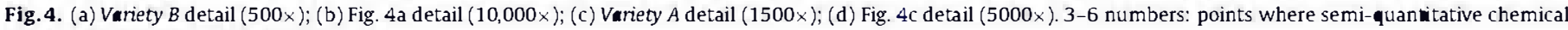
analyses have been carried out (Table 3 ).

Table 4

Quantitative chemical analysis in different points of the studied LWAs.

\begin{tabular}{|c|c|c|c|c|c|c|}
\hline \multirow{2}{*}{$\begin{array}{l}\text { LWAs } \\
\text { Points }\end{array}$} & \multirow{2}{*}{$3 . F(3)-1150-10$} & \multicolumn{3}{|c|}{$3 . F(3)-1175-10$} & \multicolumn{2}{|c|}{ 3. $F(2)-1225-15$} \\
\hline & & 2 & 3 & 4 & 5 & 6 \\
\hline \multicolumn{7}{|c|}{ Oxide (wt.\%) } \\
\hline $\mathrm{SiO}_{2}$ & 12.466 & 5.007 & 42.211 & 48.822 & 2.302 & 48.454 \\
\hline $\mathrm{Al}_{2} \mathrm{O}_{3}$ & 5.780 & 6.349 & 13.020 & 19.396 & 3.215 & 26.026 \\
\hline $\mathrm{FeO}$ & 64.563 & 86.184 & 11.403 & 6.682 & 82.318 & 4.413 \\
\hline $\mathrm{MnO}$ & 0.050 & n.d. & 0.019 & 0.003 & 0.073 & 0.024 \\
\hline $\mathrm{MgO}$ & 0.558 & 0.145 & 6.793 & 1.728 & 0.221 & 1.371 \\
\hline $\mathrm{CaO}$ & 2.306 & n.d. & 23.618 & 21.925 & 0.377 & 16.643 \\
\hline $\mathrm{Na}_{2} \mathrm{O}$ & 0.430 & n.d. & 0.166 & 0.468 & 0.005 & 0.447 \\
\hline $\mathrm{K}_{2} \mathrm{O}$ & 1.297 & n.d. & 0.496 & 0.937 & 0.153 & 0.896 \\
\hline $\mathrm{TiO}_{2}$ & 0.059 & 0.022 & 0.398 & 0.431 & 0.052 & 0.413 \\
\hline $\mathrm{NiO}$ & 0.095 & 0.005 & n.d. & n.d. & 0.074 & 0.009 \\
\hline $\mathrm{P}_{2} \mathrm{O}_{5}$ & 0.037 & n.d. & 0.135 & 0.076 & n.d. & 0.019 \\
\hline $\mathrm{SO}_{3}$ & 0.769 & 0.003 & 0.041 & n.d. & n.d. & n.d. \\
\hline $\mathrm{Cl}$ & 0.007 & n.d. & 0.005 & 0.035 & n.d. & 0.006 \\
\hline Total & 88.415 & 97.715 & 98.304 & 100.495 & 88.790 & 98.720 \\
\hline
\end{tabular}

were found in the vitrified material of varieties $B$ and $C$ (points 3 and 4, Table 4).

Finally, pyroxene group minerals (ferroan diopside and augite) appear in all the types, except in variety $C$ (Figs. 1c and 3d) and in the core of variety $B$ (Figs. $1 \mathrm{~b}$ and $3 \mathrm{c}$ ). These phases have also been identified in sintered products made from incinerator bottom and fly ash [33-35]. Pyroxenes are neo-formed phases, since the raw materials (fly ash and washing aggregate sludge) did not contain them. A possible neo-formation mechanism would be substitutions of the $\mathrm{Ca}$ in the original structure of wollastonite $\left(\mathrm{CaSiO}_{3}\right)$ by $\mathrm{Mg}$ and Fe. Wollastonite could be formed by the reaction of calcite and quartz, accompanied by $\mathrm{CO}_{2}$ release, at temperatures higher than $600-700^{\circ} \mathrm{C}$ [34]. This neo-formation mechanism has been reported for raw materials containing quartz and calcite and lacking clay minerals, such as illite [33-35]. In this study, the washing aggregate sludge is also composed of clay minerals; therefore, an alternative neo-formation mechanism could exist, such as reaction of the clay minerals with the calcium resulting from the decarbonation of calcite. The amount of pyroxenes, at $1150^{\circ} \mathrm{C}$, increases with time but is independent of temperature, and disappears when the material is vitrified (variety $C$, Fig. $3 d$, and the internal material of variety $B$, Fig. 3c). This is in agreement with previous studies [36], in which the relative intensity of the diopside and wollastonite peaks in the XRD pattern increases until $900^{\circ} \mathrm{C}$ and decreases at higher temperatures. The same occurs in relation to time, but only after at least $20 \mathrm{~min}$.

3.3. LWAs manufactured with 50\% of washing aggregate sludge and $50 \%$ of fly ash (types 3.F(2))

\subsubsection{SEM results}

All the lightweight aggregates studied that were manufactured with this composition develop an external layer of variable thickness (100-2000 $\mu \mathrm{m})$, except for 3.F(2)-1150-10. The external shell of 3.F(2)-1225-15 (Fig. 7d) is thinner than those of 3.F(2)-1175-15 (Fig. 7a) and 3.F(2)-1200-15 (Fig. 7c). As in the case of LWAs with $25 \%$ of fly ash $(3 . F(3))$, layers are formed on the surface of the aggregates during expansion, preventing the adhesion thereof [25].

LWAs with an external shell, except 3.F(2)-1150-15, are also composed of an inner glassy material that presents signs of 


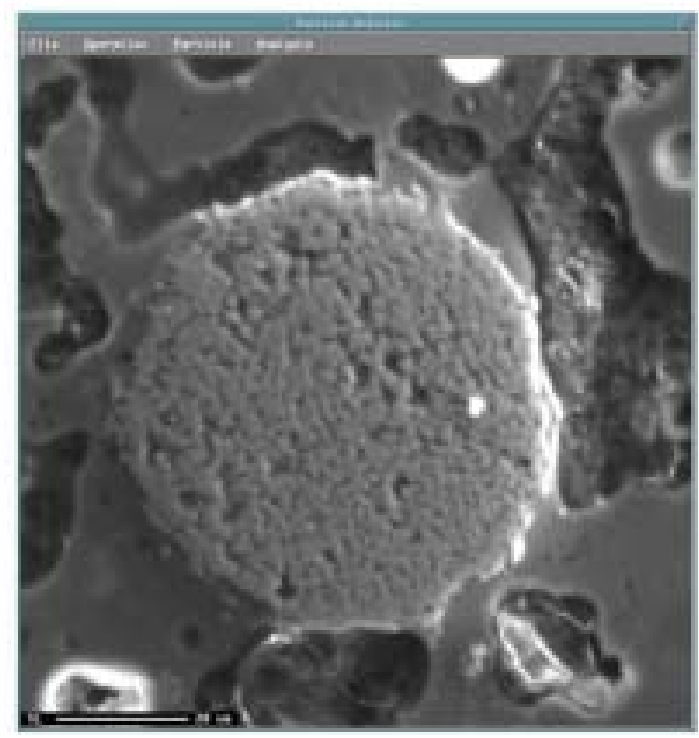

(a)

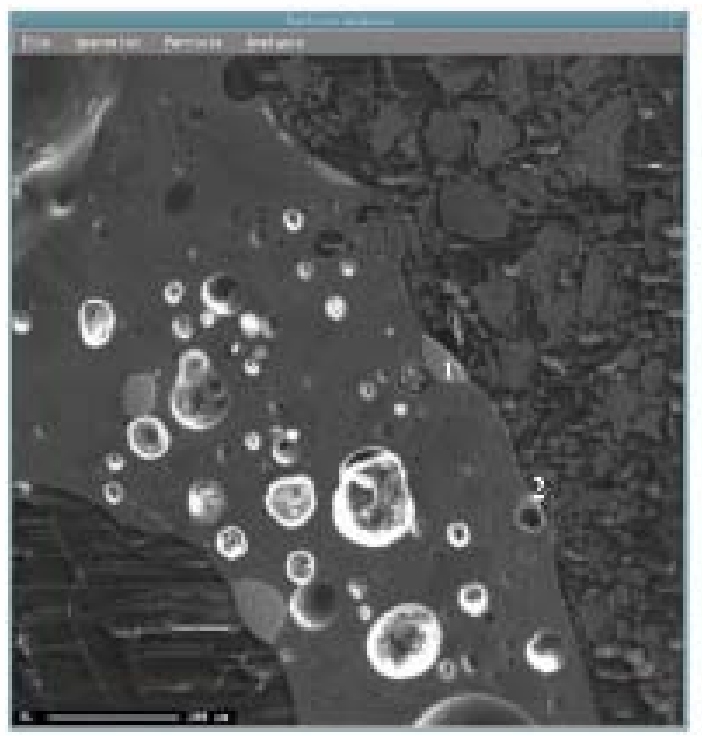

(b)



(c)

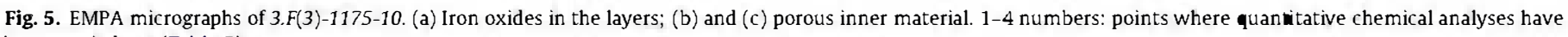
been carried out (Table 5 ).

Table 5

Quantitative chemical analysis of pyrrhotites 3.F(3)-1175-10/variety B (Fig. 5).

\begin{tabular}{|c|c|c|c|c|}
\hline \multirow{2}{*}{$\begin{array}{l}\text { LWAs } \\
\text { Points/figures where are } \\
\text { marked }\end{array}$} & \multicolumn{4}{|c|}{ 3. $F(3)-1175-10 /$ variety $B$} \\
\hline & $\begin{array}{l}1 \\
\text { (Fig. 5b) }\end{array}$ & $\begin{array}{l}2 \\
\text { (Fig. 5b) }\end{array}$ & $\begin{array}{l}3 \\
\text { (Fig. 5c) }\end{array}$ & $\begin{array}{l}4 \\
\text { (Fig. 5c) }\end{array}$ \\
\hline \multicolumn{5}{|l|}{ Element (wt:\%) } \\
\hline $\mathrm{Mn}$ & 0.047 & 0.024 & 0.047 & 0.035 \\
\hline $\mathrm{Fe}$ & 61 & 61.25 & 61.4 & 61 \\
\hline$S$ & 36.99 & 38 & 36 & 37 \\
\hline $\mathrm{Ni}$ & 0.033 & 0.078 & 0.051 & 0.067 \\
\hline As & 0.034 & 0.031 & 0.009 & 0.063 \\
\hline $\mathrm{Pb}$ & 0.25 & 0.268 & 0.252 & 0.244 \\
\hline $\mathrm{Bi}$ & 0.045 & 0.114 & 0.113 & 0.133 \\
\hline $\mathrm{Co}$ & 0.107 & 0.098 & 0.11 & 0.106 \\
\hline $\mathrm{Cu}$ & 0.058 & 0.023 & 0.043 & 0.041 \\
\hline $\mathrm{Sb}$ & 0.03 & 0.026 & 0.025 & 0.021 \\
\hline Total & 98.552 & 99.708 & 97.863 & 99.272 \\
\hline \multicolumn{5}{|l|}{ Calculated formula } \\
\hline $\mathrm{Fe}$ & 0.95 & 0.93 & 0.98 & 0.94 \\
\hline $\mathrm{S}$ & 1.00 & 1.00 & 1.00 & 1.00 \\
\hline
\end{tabular}

expansion, with pores of different sizes and not interconnected with one other. The maximum pore diameters inside 3.F(2)-117515 (Fig. 7a) and 3.F(2)-1225-15 (Fig. 7d) are, approximately, $4000 \mu \mathrm{m}$ and $5000 \mu \mathrm{m}$, respectively. Finally, the pore spatial distribution is identical to that of LWAs with $25 \%$ of fly ash (Fig. 3b-d, the largest pores located in the core and the smallest in the shell).

\subsubsection{EMPA results}

As in the case of LWAs with $25 \%$ of fly ash, the presence of Fe oxides in the shells (Fig. 7b and point 5, Table 4) and high amounts of Si and Ca oxides (point 6, Table 4), mainly in the vitrified material, are observed. Pyrrhotite $\left(\mathrm{Fe}_{1_{-}} \mathrm{S}\right)$ is also observed in the pore walls located in the glassy core.

The variation observed between the phases and compositions of the layer and the core could corroborate the fact that temperature gradients have formed inside the molten aggregates, as Lo et al. [22] have reported. 
Table 6

Mineralogical composition of LWAs. Qtz = Quartz; Hem = Hematite; Plg = Plagioclases; Prx = Piroxenes; Geh = Gehlenite .

\begin{tabular}{|c|c|c|c|c|c|}
\hline Composition- $\mathrm{T}_{\text {heating }}$-Dwell Time (Corresponding images) & $Q R$ & Hem & Plg & Prx & Geh \\
\hline 3.F(3)-1150 ${ }^{\circ} \mathrm{C}-10 \mathrm{~min}$ (Figs. $3 \mathrm{a}$ and 6 ) & ++ & & ++4 & + & \\
\hline 3. $\mathrm{F}(3)-1150^{\circ} \mathrm{C}-15 \mathrm{~min}$ (no figure) & ++ & & ++ & ++ & \\
\hline 3.F(3)-1175 ${ }^{\circ} \mathrm{C}-10 \mathrm{~min} /$ variety $A$ (Figs. $1 \mathrm{a}$ and $3 \mathrm{~b}$ ) & ++ & & +++ & + & \\
\hline 3. $\mathrm{F}(3)-1175^{\circ} \mathrm{C}-10 \mathrm{~min} /$ variety $\mathrm{B} /$ internal material (Figs. $1 \mathrm{~b}$ and $3 \mathrm{c}$ ) & ++ & & +++ & & \\
\hline 3.F(3)-1175 ${ }^{\circ} \mathrm{C}-10 \mathrm{~min} /$ variety $\mathrm{B} /$ external material (Figs. $1 \mathrm{~b}, 3 \mathrm{c}$ ande) & ++ & & +++ & + & \\
\hline 3. $F(3)-1175^{\circ} \mathrm{C}-10 \mathrm{~min} /$ variety $\mathrm{C}$ (Figs. $1 \mathrm{c}, 3 \mathrm{~d}$ and $\mathrm{f}$ ) & ++ & & ++++ & & \\
\hline $3 . \mathrm{F}(2)-1150^{\circ} \mathrm{C}-10 \mathrm{~min}$ (no figure) & ++ & + & ++++ & & \\
\hline 3. $F(2)-1150^{\circ} \mathrm{C}-15 \mathrm{~min}$ (no figure) & + & + & ++++ & & \\
\hline 3.F(2)-1175 ${ }^{\circ} \mathrm{C}-15 \mathrm{~min}$ (Fig. $7 \mathrm{a}$ ) & + & + & +++++ & & \\
\hline 3.F(2)-1200 ${ }^{\circ} \mathrm{C}-15 \mathrm{~min}$ (Fig. $7 \mathrm{c}$ ) & + & + & ++++ & & \\
\hline 3. $F(2)-1225^{\circ} \mathrm{C}-10 \mathrm{~min}$ (no figure) & + & + & ++++ & & \\
\hline 3.F(2)-1225 ${ }^{\circ} \mathrm{C}-15 \mathrm{~min}$ (Fig. $\left.7 \mathrm{~d}\right)$ & + & + & ++++ & & \\
\hline 3. $A c-1150^{\circ} \mathrm{C}-10 \mathrm{~min}$ (Fig. $8 \mathrm{a}$ and $\mathrm{b}$ ) & ++++ & & ++ & & + \\
\hline 3. Ac- $1175^{\circ} \mathrm{C}-15 \mathrm{~min}$ (Fig. $8 \mathrm{c}$ and d) & +++ & & +++ & & \\
\hline
\end{tabular}

$+=1-20 \% ;++=21-40 \% ;+++=41-60 \% ;++++=61-80 \% ;+++++=81-100 \%$.

Therefore, for aggregates composed of washing aggregate sludge and fly ash, the heating temperature and the dwell time affect both the overall structure of the aggregates and the existence of a reducing microenvironment in the vitrified inner area (only in the pores).

\subsubsection{Mineralogy results}

All the LWAs manufactured with 50\% of fly ash present quartz, hematite and plagioclases (Table 6). Like quartz, hematite could be present in the LWAs as a relic of the raw materials [8], since this mineral is present in the LWAs manufactured with $50 \%$ of fly ash but has not been detected by XRD in the LWAs manufactured with $25 \%$ of fly ash. It has been reported that, at $370-700^{\circ} \mathrm{C}$, hematite may result from the transformation of magnetite [37-39]; therefore, it is possible that a portion of the total hematite was neoformed, during the pre-heating process of the LWAs (approximately $200-800^{\circ} \mathrm{C},[8]$ ), from the magnetite in the fly ash [8]. This process can occur both in the presence or absence of oxygen [40]. On the contrary, the probability that hematite is newly formed from pyrite (represented by $4 \mathrm{FeS}_{2}+11 \mathrm{O}_{2} \leftrightarrow 2 \mathrm{Fe}_{2} \mathrm{O}_{3}+8 \mathrm{SO}_{2}$ ) is very low, since the inner pores provide a reducing environment (pyrrhotite is found in the inner walls thereof). The origin of the plagioclases and the decrease in the intensity of the quartz peak in the XRD patterns could be the same as that described for LWAs with $25 \%$ of fly ash (type $3 . F(3)$ ).

3.4. LWAs manufactured with 97.5\% of washing aggregate sludge and 2.5\% of used motor oil (types 3.Ac)

\subsubsection{SEM and EMPA results}

The SEM and BSE-EMPA images show the fracture surface of 3.Ac-1150-10 (Fig. 8a-b) and 3.Ac-1175-15 (Fig. 8c-d) LWAs. They do not have a physically distinct external layer or clear signs of bloating, because there was not an appropriate balance between the gas pressure and the viscosity of the molten phase [25]. In sample 3.Ac-1175-15, an incipient vitrification is observed, with relics of quartz grains surrounded by the silicate matrix (Fig. 8d). There is also porosity, small elongated voids (of up to $100 \mu \mathrm{m}$ ), formed as a result of gas release from the raw materials (not trapped, as

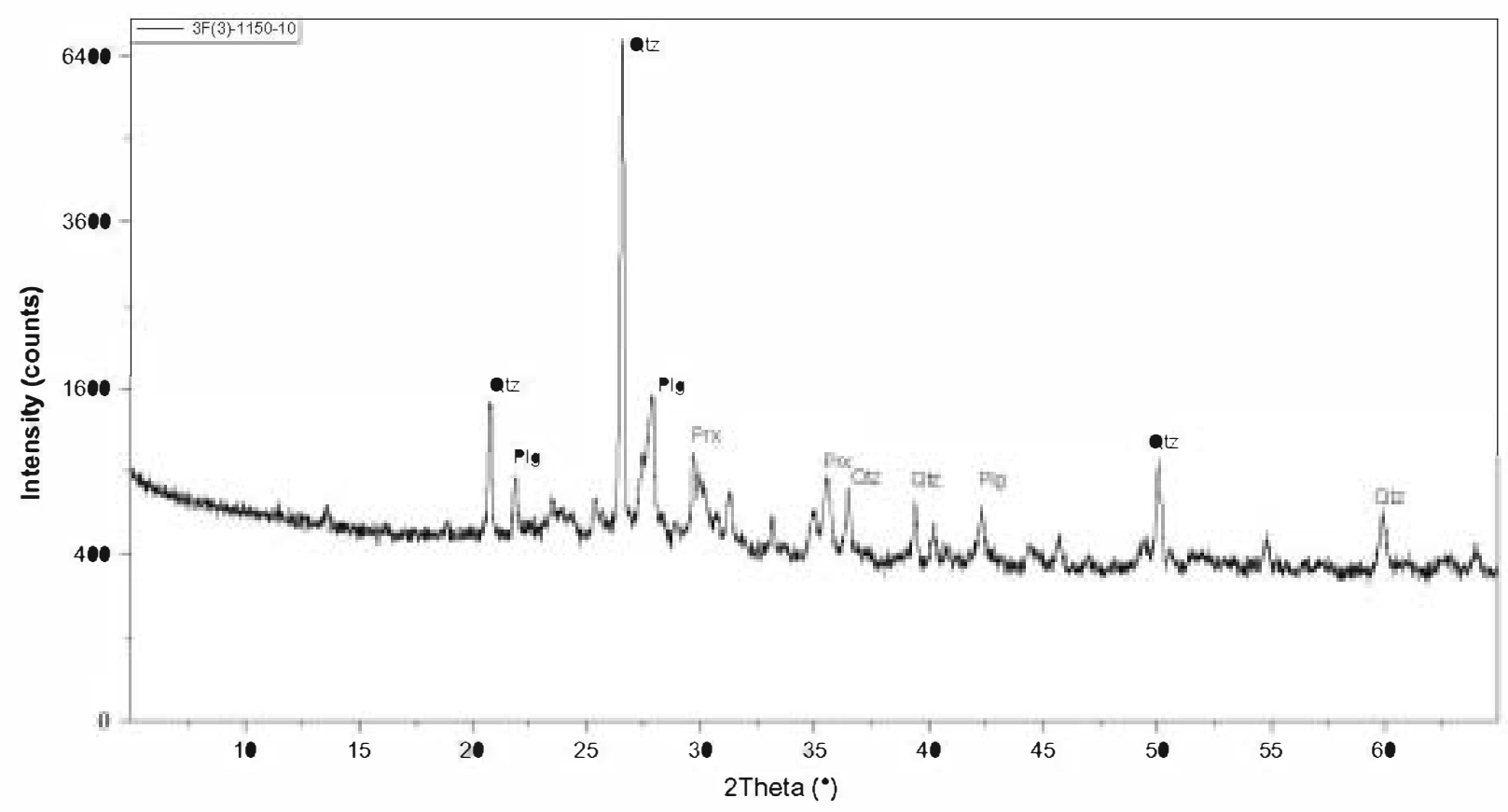

Fig. 6. XRD pattern of 3.F(3)-1150-10 sample. Qtz: Quartz; Plg: Plagioclase; Prx: Pyroxene. 


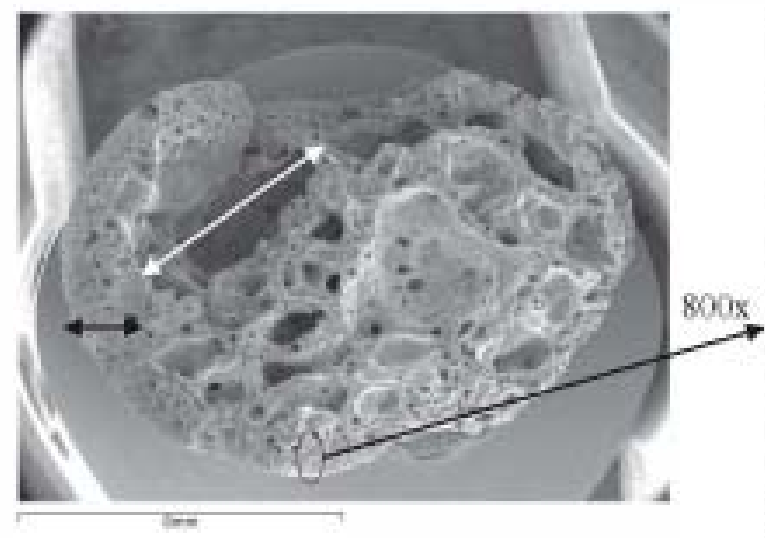

(a)

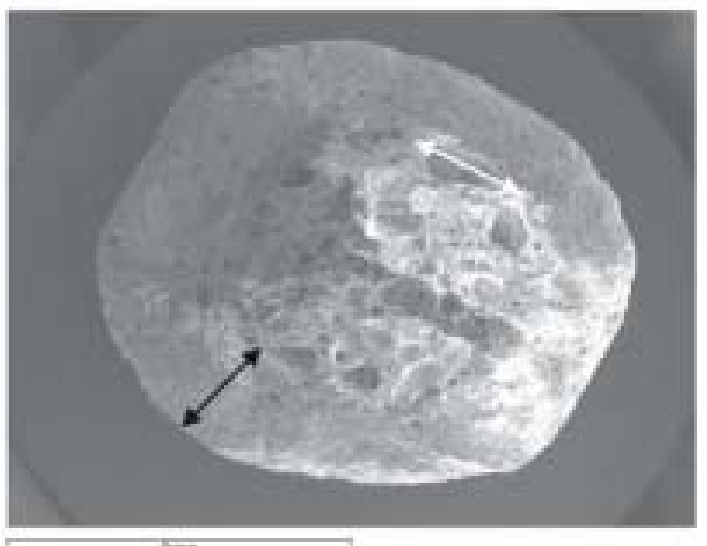

(c)

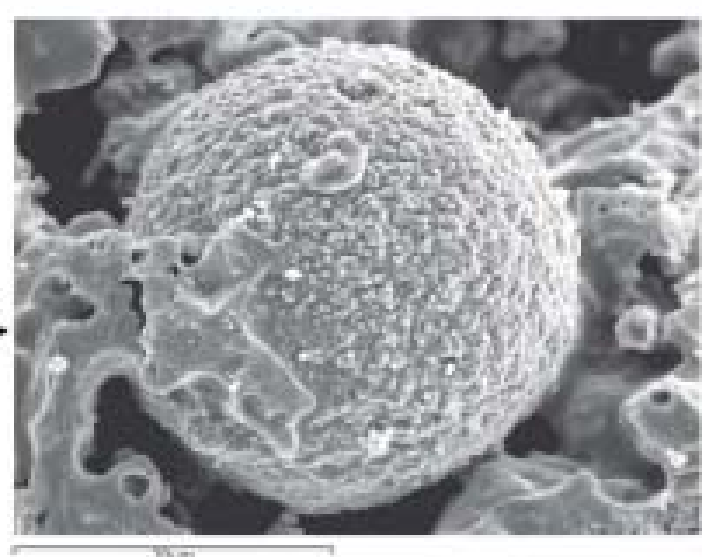

(b)

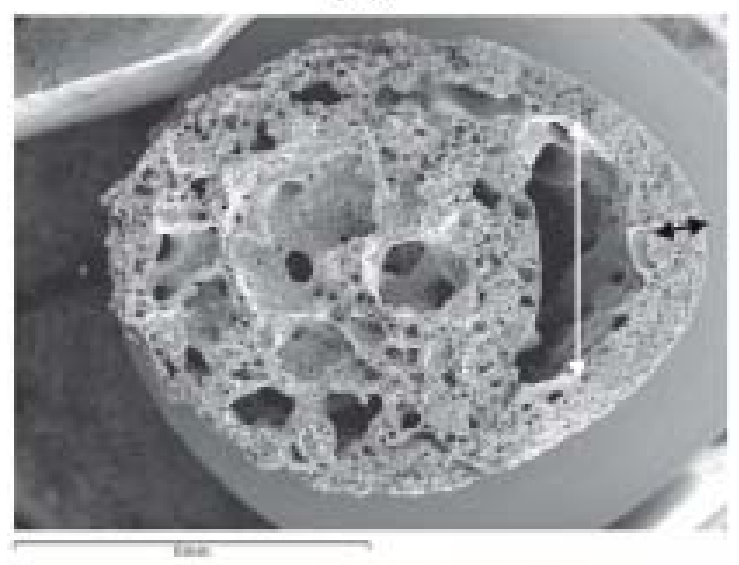

(d)

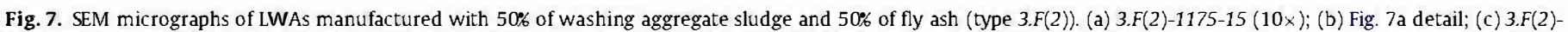
1200-15 (12x); and (d) 3.F(2)-1225-15 (10x). White arrow: maximum pore diameter; black arrow: maximum layer thickness.

bloating is not observed). Iron sulfide is not observed either, since sulfur is not present in the washing aggregate sludge.

Sample 3.Ac-1150-10 (Fig. 8a-b), with a lower heating temperature and a shorter dwell time, is similar to sample 3.Ac-1175-15 (Fig. $8 \mathrm{c}-\mathrm{d}$ ), but contains traces of iron oxide in the external areas.

Contrary to the case of the LWAs manufactured with fly ash, the loss on ignition of aggregates made with used motor oil was not related to the heating temperature of the LWAs [8]. Thus, the differences observed in the macro properties and the microstructure of 3.Ac-1150-10 (Fig. 8a-b) and 3.Ac-1175-15 (Fig. 8c-d) could be caused by variations in the pressure of the released gas and the viscosity of the raw materials at $1150^{\circ} \mathrm{C}$ and at $1175^{\circ} \mathrm{C}$. Therefore, the LWAs released the same amount of gases (LOI value of approximately $18 \%,[8])$, but these were not trapped to the same extent.

\subsubsection{Mineralogy results}

Crystalline phases in aggregates 3.Ac-1150-10 (Fig. 8a-b) and 3.Ac-1175-15 (Fig. 8c-d) are shown in Table 6. Quartz and plagioclase group minerals occur in both aggregates. Gehlenite $\left(\mathrm{Ca}_{2} \mathrm{Al}_{2}\right.$. $\mathrm{SiO}_{7}$ ) is also detected in 3.Ac-1150-10. Quartz could be considered as a relic of the raw material, whereas the plagioclases and gehlenite would be neo-formed minerals produced after the decomposition of calcite, as in the case of LWAs with $25 \%$ of fly ash (types 3.F(3)). A similar reaction was reported by Stoch et al. [30]. Finally, we may conclude that an increase in the temperature and dwell time causes mineralogical changes in the LWAs made with used motor oil, since gehlenite disappears and the amount of plagioclases increases. Previous studies have shown the presence of gehle- nite in samples sintered at relatively low temperatures (1000$1100^{\circ} \mathrm{C}$ ), which becomes destabilized at $1200^{\circ} \mathrm{C}[41,42]$. In turn, crystallization of anorthite by the melting of gehlenite at $1200^{\circ} \mathrm{C}$ was observed. This behavior could be responsible for the mineralogical trend observed.

The presence of gehlenite in 3.Ac-1150-10 and the lack thereof in $3 . F(3)-1150-10$ and $3 . F(2)-1150-10$ (Table 6 ) could be due to a greater amount of calcite (i.e. available calcium) in 3.Ac-1150-10 (97.5\% of WS) than in $3 . F(3)-1150-10$ (75\% of WS) and $3 . F(2)-$ $1150-10$ (50\% of WS). Stoch et al. [30] reported that the mineralogical composition of sintered samples is dependent on the amount of calcium-bearing compound introduced. Thus, the crystalline phases were represented by anorthite when $10 \%$ of a calcium-bearing compound was added, whereas the amount of gehlenite was greater than that of anorthite when $30 \%$ of a calcium-bearing compound was added.

\subsection{Influence of the microstructure and the mineralogy on the properties of the LWAs}

\subsubsection{Bloating index}

The chemical composition of the raw materials and mixtures was reported in González-Corrochano et al. [8]. Generally, changes in viscosity at high temperatures are dependent on the $\mathrm{CaO}$ and $\mathrm{MgO}$ contents in the raw materials. As $\mathrm{CaO}$ and $\mathrm{MgO}$ contents are between $10 \%$ and $11 \%$ or less in the $3 . F(3)$ and $3 . F(2)$ mixtures, the granules do not show a sudden change in viscosity even at high temperatures [24]; therefore, trapping of gases may occur within a 


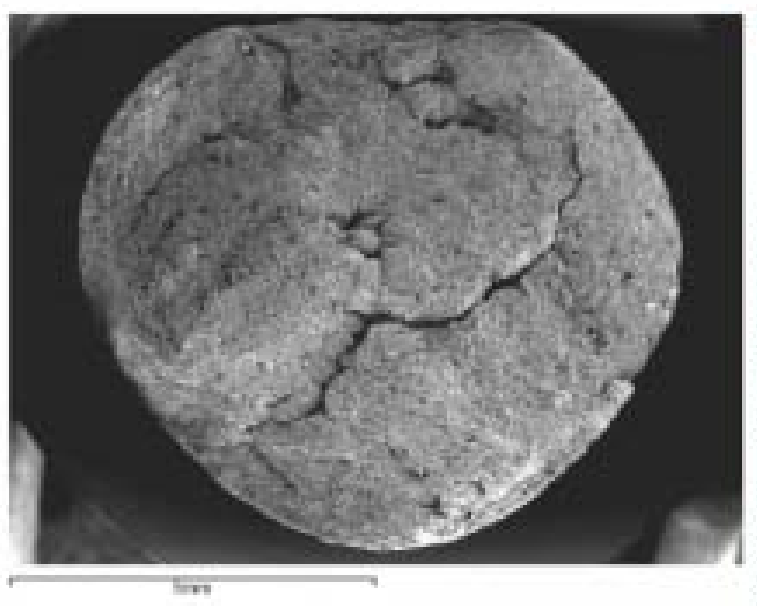

(a)

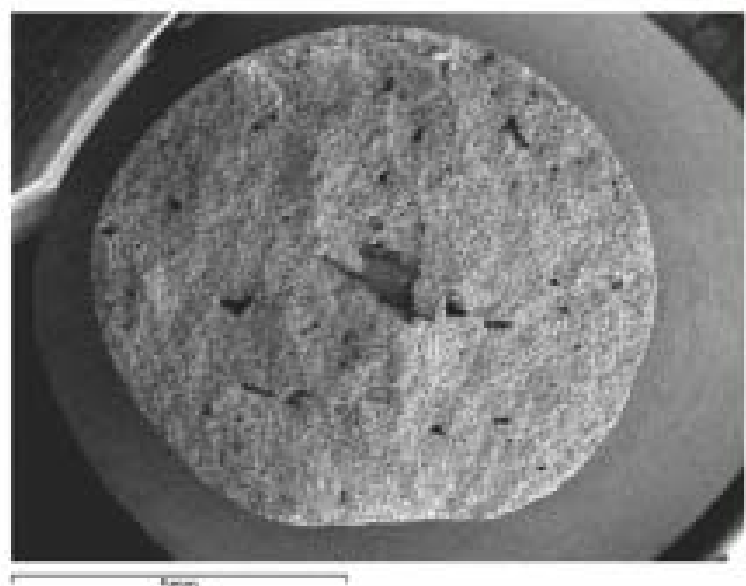

(c)

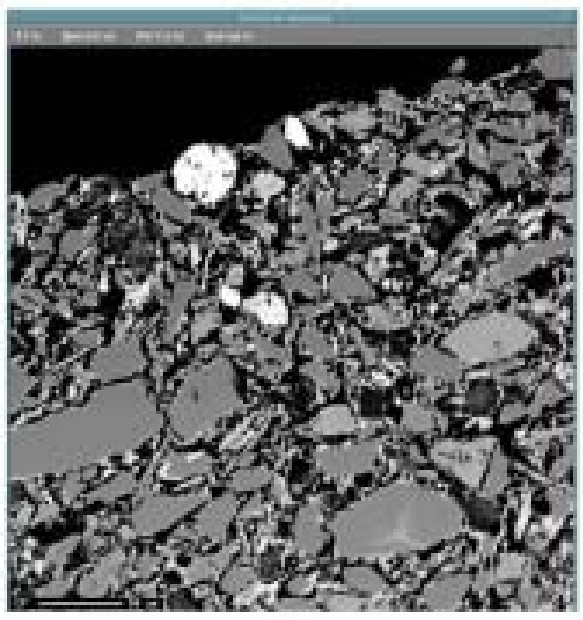

(b)

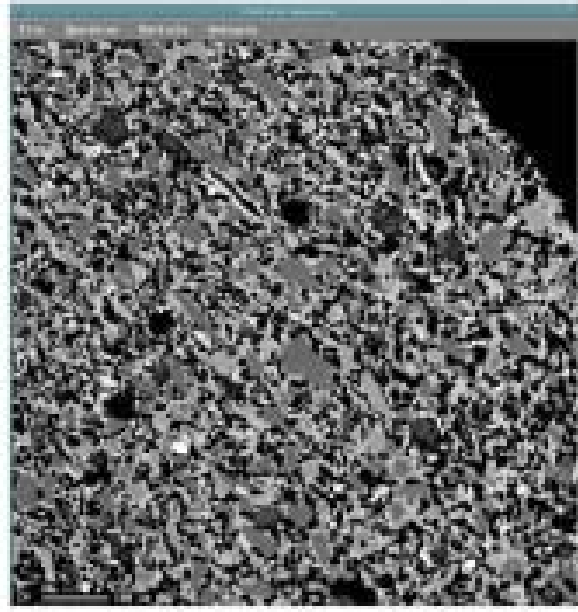

(d)

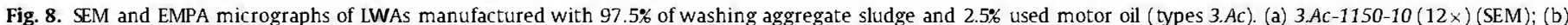
3.AC-1150-10 (EMPA); (c) 3.Ac-1175-15 (12×) (SEM); and (d) 3.Ac-1175-15 (EMPA).

broad temperature range. This, combined with the release of gases that occurs at all the heating temperatures [8], appears to be the main reason why bloated structures form within a broad temperature range before they melt (Figs. 3 and 7). It has also been reported that the melting point tends to become higher as the $\mathrm{Al}_{2} \mathrm{O}_{3}$ to $\mathrm{SiO}_{2}$ ratio increases [25]. Thus, the melting point of LWAs with $25 \%$ of fly ash is lower than that of LWAs with 50\% of fly ash because their $\mathrm{Al}_{2} \mathrm{O}_{3}$ to $\mathrm{SiO}_{2}$ ratio is lower.

LWAs with fly ash (types $3 . F(3)$ and $3 . F(2)$ ) present the same crystalline phases before the bloating phenomenon ( $\mathbf{B I}<0$, Fig. 9a and Table 6) and after the bloating phenomenon (BI $>0$, Fig. 9a and Table 6$)$. In the case of 3.F(2) LWAs, the mineral phases are quartz, plagioclase and hematite. The appearance of hematite, a mineral that can release gases, after bloating could be due to: (i) part of this mineral in the green pellets is not consumed; (ii) the reaction involved is reversible $\left(6 \mathrm{Fe}_{2} \mathrm{O}_{3} \leftrightarrow 4 \mathrm{Fe}_{3} \mathrm{O}_{4}+\mathrm{O}_{2}\right.$, [27]), and magnetite could undergo a structural change to hematite [38]; (iii) hematite crystals may be occluded in an amorphous silica matrix after calcination in the temperature range 900-1300 ${ }^{\circ} \mathrm{C}$ [43].

\subsubsection{Dry particle density}

Fig. 9b shows the dry density $\left(\rho_{\mathrm{rd}}\right)$ values of the LWAs studied, with the SEM micrograph number. LWAs with $25 \%$ of fly ash present a decrease in $\rho_{\text {rd }}$ with temperature, because the IOI of the pel- lets is higher at $1175^{\circ} \mathrm{C}$ than at $1150^{\circ} \mathrm{C}$ (the mass of aggregates is lower) and because the BI is higher (the volume of aggregates is higher) [8]. The latter argument is supported by Fig. 3, in which the presence of larger pores at $1175^{\circ} \mathrm{C}$ (Fig. 3b-d) than at $1150^{\circ} \mathrm{C}$ (Fig. 3a) can be observed. Fig. 7 also shows that the microstructure affects the $\rho_{\text {rd }}$ trend of the LWAs with $50 \%$ of fly ash: the increase in $\rho_{\mathrm{rd}}$ at $1200^{\circ} \mathrm{C}$ occurs because, at this temperature and dwell time, the aggregates present a slightly lower BI than that at $1175^{\circ} \mathrm{C}$ (Fig. 9a), as shown by the lower proportion of inner pores and a smaller size in Fig. 7c as compared to Fig. 7a and d. The dry particle density of 3.Ac aggregates increases with the heating temperature (Fig. 9b) because the IOI remains constant [8], but the BI decreases (the size of the LWAs is smaller, Fig. 9a). The results of the microstructure study of this type of LWAs are in accordance with those previously mentioned: $3 . A c-1175-15$ presents an incipient vitrification, with more compact material (Fig. $8 \mathrm{c}-\mathrm{d}$ ) than 3.Ac-1150-10 (Fig. 8a-b).

\subsubsection{Water absorption}

The water absorption and the strength of the LWAs are very important factors in controlling the behavior of lightweight aggregate concrete [23]. According to Mehta and Monteiro [11], unlike normal-weight concrete, the aggregate, and not the interfacial transition zone, where, due to the pozzolanic reaction, the bond 
(a)



(c)



(b)

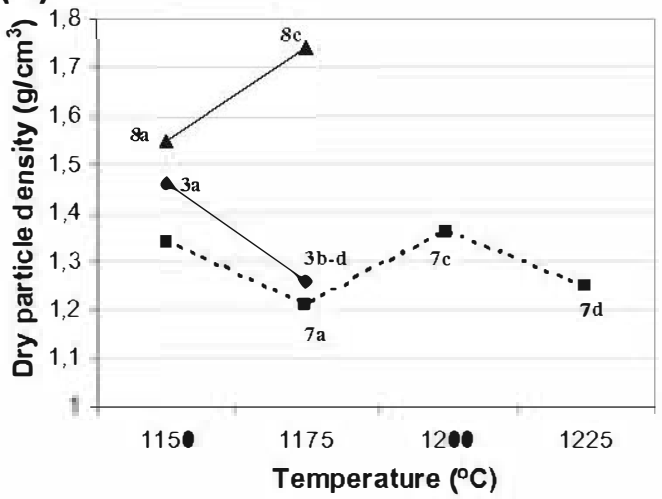

(d)

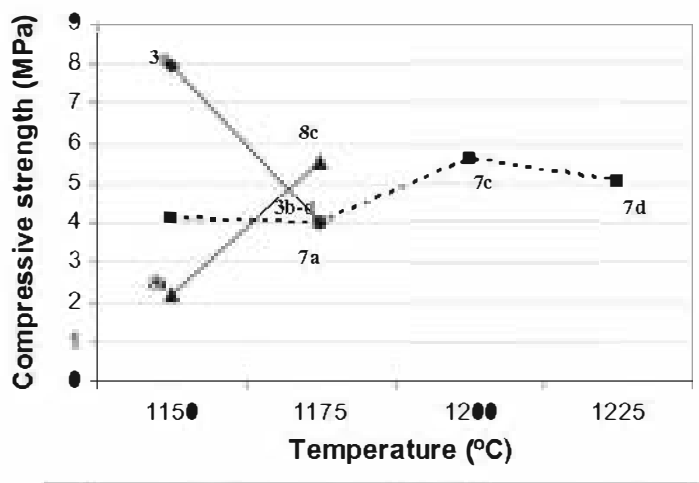

$3 . \mathrm{F}(3) / 10 \mathrm{~min} \cdot-\cdot-3 . \mathrm{F}(2) / 15 \mathrm{~min} \longleftarrow \mathrm{Ac}^{\mathrm{a}}$

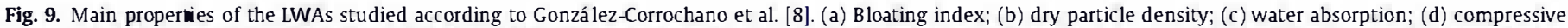
strength. ${ }^{\circ} \mathrm{Dw}$ ell time of 10 and $15 \mathrm{~min}$ at $1150^{\circ} \mathrm{C}$ and $1175^{\circ} \mathrm{C}$, respectively. Number and letter: figure with the micros ucture of the LWA that have that value.

strength between aggregate/cement is stronger than the individual LWA particles, is the weakest component of the system. Furthermore, knowledge about LWA absorption capacity values is necessary to correct the batch water and aggregate proportions in concrete mixtures. It is also necessary to evaluate the internal curing that the water absorbed by the LWAs can provide to the cement to promote the hydration and maintain saturated capillary pores in the paste. Internal curing is one solution to the problems (increase in internal stresses and increased propensity for early age cracking) for low water-to-cement ratio concretes where external curing is ineff ective [44].

A particle with a vitrified surface or isolated pores tends to absorb little water, whereas one with connected or open pores will absorb water like a sponge [45]. The size and the number of pores also determine the water absorption rate [29]. In lightweight aggregates manufactured with $25 \%$ and $50 \%$ of fly ash, the temperature increase caused an increase in the size of the pores but, this notwithstanding, a reduction in the water absorption values also occurred (Fig. 9c). In this case, it is due to the fact that water absorption is more related to the presence of an external vitrified layer and the type (open or closed) of pores in the external layers than to the size and/or number of pores. At a temperature above $1150^{\circ} \mathrm{C}$, a sintered-vitrified layer forms on the particle surface (Figs. 3 and 7) and the entry of water into the inner pores is blocked (regardless of their connectivity and size) [45], which leads to LWA water absorption measurements below $15 \%$. These results agree with previous works [23].

In the case of the LWAs made with used motor oil (type 3.Ac), the reduction in the absorption capacity is more related to the porosity (open or closed) than to the presence of a vitrified layer since, as Fig. 8 shows, this type of LWAs does not present an external shell. In Fig. 8, it may also be observed that open porosity is less abundant in LWAs manufactured at $1175^{\circ} \mathrm{C}$ (Fig. 8d) than at $1150^{\circ} \mathrm{C}$ (Fig. 8b); therefore, the water absorption decreases with temperature.

More than the $60 \%$ of the $24 \mathrm{~h}$ water absorption takes place during the first hour and early hydration can produce micro-cracking at the aggregate/cement interface in lightweight concrete $[12,22]$. Therefore, a prewetting process of the LWAs with the highest $W_{24 h}$ values, such as 3.F(3)-1150-10 and 3.Ac-1150-10, would be advisable in order to prevent the formation of this micro-cracking.

\subsubsection{Crushing strength}

The crushing strength values of the lightweight aggregates studied are presented in Fig. 8d, with the corresponding SEM image numbers.

Although this property is mainly influenced by the porosity as it can be seen by the correlation between Fig. 9b and c, differences in microstructure are not the only reason for the variation in crushing strength values; they could be correlated to other factors, such as cracks and internal defects due to thermal stresses and changes in the mineralogical composition [23]. The formation of the glass phase has been found to prevent the increase in water absorption and the decrease in strength, although pores are formed inside the LWAs [25]. In our case, the formation of the glass phase is effective in reducing water absorption, but, on the other hand, the compressive strength values are worse at $1175^{\circ} \mathrm{C}$ than at $1150^{\circ} \mathrm{C}$ for LWAs with $25 \%$ of fly ash, due to the cracks caused by thermal stress observed on the surface of 3.F(3)-1175-10/variety B (Fig. 1b). Besides, they are dominated by the presence of larger pores that be- 
gin to coalesce and form irregular-shape voids (Fig. $3 c$ and d). The material still has a relatively high strength and the combination of its properties suggests that it may also be suitable for use as a lightweight aggregate in some industrial fields, such as geotechnical applications, prefabricated lightweight structures and lightweight insulating concretes [8].

Larger coalescing pores are also present in 3.F(2)-1175-15 and 3.F(2)-1225-15 (Fig. 7a and d, respectively) and the compressive strength data show the same trends as for $3 . F(3)$, for the same reasons. This material is also suitable for the same applications as the previous one [8].

Sample 3.Ac-1175-15 presents a higher compressive strength than 3.Ac-1150-10 (Fig. 9d) mainly because of its lower total porosity (Fig. 8c-d). Moreover, it has been reported that calcium silicates provide advantageous ceramic properties [30]. Calcium feldspars are present in larger amounts in 3.Ac-1175-15 than in 3.Ac-115010 (Table 6). The consumption of quartz during the formation of the glassy phase could be another reason for the increase in the compressive strength of 3.Ac-1175-15 as compared to 3.Ac-115010 (Fig. 9d), since it has been reported that larger amounts of silicate glass improve the strength of clay-based ceramics [46].

\section{Con clusions}

(i) The raw materials and heating temperature affect the degree of vitrification of the material that forms the lightweight aggregate and control the formation of an external layer separated from an inner pore-containing core.

(ii) Pores located in the vitrified material are location sites for neo-formed crystalline phases such as pyrrhotite. In the non-vitrified material, the presence of iron oxides in rounded aggregates is systematically observed.

(iii) The mineralogical analysis reveals that the main crystalline phases identified in the LWAs are quartz, hematite and neo-formed phases from the plagioclase and pyroxene groups, with a minor presence of gehlenite. The amount of quartz decreases and the amount of plagioclase increases as the heating temperature and the dwell time increase.

(iv) The microstructure of the LWAs studied is related to:

- Their bloating index: lower BI values reflect a lower proportion of inner pores and a smaller pore size. They can also reflect an incipient vitrification and a more compact material.

- Their dry particle density: the presence of larger pores may be observed when the LWAs present a decrease in $\rho_{\text {rd }}$.

- Their water absorption: when a sintered-vitrified external layer is not present, $W_{24 h}$ values are dependent on the size and amount of each type of pore in the LWAs.

- Their crushing strength: cracks, total porosity and the presence of larger pores cause a worsening of $S$ values.

(v) The mineralogical composition of these LWAs is related to:

- Their water absorption: the formation of the glass phase is effective in reducing water absorption.

- Their crushing strength: calcium feldspars and the consumption of quartz improve the $S$ values.

Although a detailed microstructural and mineralogical study of LWAs has been carried out in this work, studies of the hydrated cement paste, the interfacial transition zone and the interrelationships between them are essential to control the properties of concrete [11]. For this reason, this work is a preliminary approach to understanding the possible characteristics of concretes manufactured with the LWAs studied. Further studies will be carried out in order to better determine the applications of the LWAs obtained.

\section{Acknowledgments}

The financial support from the Junta de Comunidades de CastillaLa Mancha (Project PBI-05-044 and Project PCI08-0027) and from the Obra Social Caja Madrid of Spain are gratefully acknowledged.

\section{References}

[1] UNE-EN-13055-1. Lightweight aggregates. Part 1: lightweight aggregates for concrete, mortar and grout; 2002.

[2] DêGennaro R, Cappelletti P, Cerri G, DêGennaro M, Dondi M, Langella A. Zeolitic tuffs as raw materials for lightweight aggregates. Appl Clay Sci 2004;25(1-2):71-81.

[3] Riley CM. Relation of chemical properties to the bloating of clays. J Am Ceram Soc 1951;34:121-8.

[4] Fragoulis D, Stamatakis MG, Chaniotakis E, Columbus G. Characterization of lightweight aggregates produced with clayey diatomite rocks originating from Greece. Mater Charact 2004;53(2-4):307-16.

[5] González-Corrochano B, Alonso-Azcárate J, Rodas M. Production of lightweight aggregates from mining and industial wastes. J Environ Manage 2009;90:2801-12.

[6] Wainwright PJ, Cresswell DJF, Van der Sloot HA. The production of synthetic aggregate from a quarry waste using an innovative style rotary kiln. Waste Manage Res 2002;20(3):279-89.

[7] Baykal G, Doven AG. Utilization of fly ash by pelletization process; theory, application areas and research results. Resour Conserv Recycling 2000;30(1):59-77

[8] González-Corrochano B, Alonso-Azcárate J, Rodas M. Characterization of lightweight aggregates manufactured from washing aggregate sludge and fly ash. Resour Conserv Recycling 2009;53:571-81.

[9] Mangialardi T. Sintering of MSW fly ash for reuse as a concrete aggregate. J Hazard Mater 2001;83(1-3):225-39.

[10] Fakhfakh E, Hajjaji W, Medhioub M, Rocha F, López-Galindo A, Setri M, et al. Effects of sand addition on production of lightweight aggregates from Tunisian smectite-rich clayey rocks. Appl Clay Sci 2007;35:228-37.

[11] Mehta PIK, Monteiro PJM. Concrete, microstructure, properties and materials. New York: McGraw-Hill Companies; 2006.

[12] Swamy RN, Lambert $H$. The microstructure of Lytag aggregate. Int J Cem Compos Lightweight Concr 1981;3(4):273-82.

[13] Feret R. Sur la forme et letat de surface des êlêment inertes des bêtons. Annales LT.B.T.P.; Mars-Avril 1937.

[14] Influencia Carrillo JS. Influencia de la naturaleza mineralógica de las adiciones en el comportamiento de la pasta endurecida del Cemento Portland. L Acción del hielo. Rev Obras Públicas 1980:861-7.

[15] Farran J. Contribution minêralogique à lêtude de ladherênce entre les constituant hydrates des ciments et les materiaux enrobês. Rev Matêr Construct 1956;490-491:155-72. and 492:191-209.

[16] Laursen K, White TJ, Cresswell DJF, Wainwright PJ, Barton JR. Recycling of an industrial sludge and marine clay as light-weight aggregate. J Environ Manage 2006;80:208-13.

[17] Richart FE, Jensen VP. Tests on plain and reinforced concrete made with Haydite aggregates. Engineering Experiment Station. Bulletin No. 237, p. 7-79. University of Illinois, 1931.

[18] Zhang $\mathrm{MH}, \mathrm{Gjorv} \mathrm{OE}$. Characteristics of lightweight aggregate for concrete. ACI Mater J 1991;88:150-8.

[19] Yasuda Y. Sewage-sludge utilization in Tokyo. Water Sci Technol 1991;23(1012):1743-52.

[20] UNE-EN-1097-6. Test for mechanical and physical properties of aggregates. Part 6: determination of particle density and water absorption, 2000.

[21] Li Y, Wu D, ZhangJ, Chang I, Fang Z, Shi Y. Measurement and statistics of single pellet mechanical strength of differently shaped catalysts. Powder Technol $2000 ; 113: 176-84$

[22] Lo Y, Gao XF, Jeary AP. Microstructure of pre-wetted aggregate on lightweight concrete. Build Environ 1999;34:759-64.

[23] Wasserman R, Bentur A. Effect of lightweight fly ash aggregate microstructure on the strength on concretes. Cem Concr Res 1997;27(4):525-37.

[24] Chiou IJ, Wang KS, Chen CH, Lin YT. Lightweight aggregate made from sewage sludge and incinerated ash. Waste Manage 2006;26(12):1453-61.

[25] Mun KJ. Development and tests of lightweight aggregate using sewage sludge for nonstructural concrete. Construct Build Mater 2007;21:1583-8.

[26] Mun KJ. A study on using expanded clay and organic sludge for manufacturing of super lightweight aggregate (in Korean). In: Proceedings of the conference of the Korea society of waste management, Seoul, Korea, 2002. p. 243-6.

[27] Soh YS, Mun KJ. Manufacturing of sintered lightweight aggregate using paper mill sludge ash (in Korean). J Korea Concr Inst 1991;13(1):114-9.

[28] Utley RW, Lovell HI, Spicer TS. The preparation of coal refuse for the manufacture of lightweight aggregate. Trans Soc Mining Eng AIME $1965 ; 232(4): 346-52$.

[29] Huang SC, Chang FC, Lo SI, Lee MY, Wang CF, Lin JD. Production of lightweight aggregates from mining residues, heavy metal sludge, and incinerator fly ash. J Hazard Mater 2007;144(1-2):52-8.

[30] Stoch L, Kordek M, Nadachowski F. Processing of some non-conventional ceramic raw materials and by-products. Ceram Int 1986;12:213-20. 
[31] Halstead PE, Moore AE. The thermal dissociation of calcium hydroxide. J Chem Soc 1957:3873-5.

[32] Mangialardi T, Piga L, Schena G, Sirini P. Characteristics of MSW incinerator ash for use in concrete. Environ Eng Sci 1998;15(4):291-7.

[33] Cheeseman CR, Monteiro da Rocha S, Sollars C, Bethanis S, Boccaccini AR. Ceramic processing of incinerator bottom ash. Waste Manage 2003;23:907-16.

[34] Cheeseman CR, Makinde A, Bethanis S. Properies of lightweight aggregate produced by rapid sintering of incinerator bottom ash. Resour Conserv Recycling 2005;43:147-62.

[35] Poletini A, Pomi R, Trinci L, Muntoni A, Lo Mastro S. Engineering and environmental properties of thermally treated mixtures containing MSWI fly ash and low-cost additives. Chemosphere 2004;56:901-10.

[36] Romero M, Rincón JM, Rawlings RD, Boccaccini AR. Use of vitrified urban incinerator waste as raw material for production of sintered glass-ceramics. Mater Res Bull 2001;36:383-95.

[37] Goyal RN, Kaur D, Pandey AK. Growth and characterization of iron oxide nanocrystalline thin films via low-cost ultrasonic pyrolysis. Mater Chem Phys $2009 ; 116: 638-44$.

[38] Mitov I, Cherkezova-Zheleva Z, Mitrov V. Comparative study of the mechanochemical activation of magnetite $\left(\mathrm{Fe}_{3} \mathrm{O}_{4}\right)$ and maghemite $\left(\gamma-\mathrm{Fe}_{2} \mathrm{O}_{3}\right)$. Phys Status Solid (a) 1997;161(2):475-82.
[39] Nasrazadani S, Raman A. The application of infrared spectroscopy to the study of rust systems - II. Study of cation deficiency in magnetite $\left(\mathrm{Fe}_{3} \mathrm{O}_{4}\right)$ produced during its transformation to maghemite $\left(\gamma-\mathrm{Fe}_{2} \mathrm{O}_{3}\right)$ and hematite $\left(\alpha-\mathrm{Fe}_{2} \mathrm{O}_{3}\right)$. Corros Sci 1993;34(8):1355-65.

[40] Mazo-Zuluaga J, Barrero CA. Diaz-Terán J, Jerez A, Restrepo J, Morales AL. Transformación magnetita-hematita inducida têrmicamente. Rev Colombiana Física $2001 ; 33(2): 230-3$.

[41] Kurama $\mathrm{S}$, Ozel $\mathrm{E}$. The influence of different $\mathrm{CaO}$ source in the production of anorthite ceramics. Ceram Int 2009;35:827-30.

[42] Okado K, Watanabe N, Jha KV, Kameshima Y, Yasumori A, MacKenzie KJD. Effects of grinding and firing conditions on $\mathrm{CaAl}_{2} \mathrm{Si}_{2} \mathrm{O}_{8}$ phase formation by solid-state reaction of kaolinite with $\mathrm{CaCO}_{3}$. Appl Clay Sci 2003;23:329-36.

[43] Bondioli F, Ferrari AM, Leonelli C, Manfredini T. Syntheses of $\mathrm{Fe}_{2} \mathrm{O}_{3} /$ silica red inorganic inclusion pigments for ceramic applications. Mater Res Bull 1998;33:723-9.

[44] Bentz DP, Lura P, Roberts JW. Mixture proportioning for internal curing. Concr Int 2005;22(2):35-40.

[45] Hung MF, Hwang CL. Study of fine sediments for making lightweight aggregate. Waste Manage Res 2007;25:449-56.

[46] Sglavo VM, Maurina S, Conci A, Salviati A, Carturan G, Cocco G. Bauxite "red mud" in the ceramic industry. Part 2: production of clay-based ceramics. J Eur Ceram Soc 2000;20:245-52. 